\title{
The Italian Society of Rheumatology clinical practice guidelines for the diagnosis and management of gout
}

\author{
N. Ughi',2, I. Prevete ${ }^{1,3}$, R. Ramonda ${ }^{4}$, L. Cavagna 5 , G. Filippou ${ }^{6}$, M. Manara $^{1,2}$, \\ A. Bortoluzzi ${ }^{1,6}$, S. Parisi ${ }^{1,7}$, A. Ariani ${ }^{1,8}$, C.A. Scirèè, \\ ${ }^{1}$ Epidemiology Unit, Italian Society for Rheumatology, Milan, Italy; ${ }^{2}$ Division of Clinical Rheumatology, \\ Centro Specialistico Ortopedico-Traumatologico Gaetano Pini CTO ASST Gaetano Pini, Milano, Italy; \\ ${ }^{3}$ Rheumatology Unit, Azienda Ospedaliera San Camillo-Forlanini, Roma, Italy; ${ }^{4}$ Rheumatology Unit, \\ Department of Medicine-DIMED, University Hospital of Padua, Italy; ${ }^{5}$ Department of Rheumatology, \\ University and IRCCS Foundation Policlinico S. Matteo, Pavia, Italy; ${ }^{6}$ Department of Medical Sciences, \\ Rheumatology Section, University of Ferrara, Azienda Ospedaliero-Universitaria Sant'Anna di Cona, Ferrara, \\ Italy; ${ }^{7}$ Rheumatology Unit, Azienda Ospedaliera Città della Salute e della Scienza di Torino, Italy; ${ }^{8}$ Department \\ of Medicine, Internal Medicine and Rheumatology Unit, Azienda Ospedaliero-Universitaria di Parma, Italy
}

\begin{abstract}
SUMMARY
Gout is a chronic disease with an increased risk of premature death related to comorbidities. Treatment of gout has proved suboptimal and clinical practice guidelines (CPGs) are expected to have a key role in achieving improvement. Since new evidence has become available, the Italian Society for Rheumatology (SIR) has been prompted to update the 2013 recommendations on the diagnosis and management of gout.

The framework of the Guidelines International Network Adaptation Working Group was adopted to identify, appraise (AGREE II), synthesize, and customize the existing gout CPGs to the needs of the Italian healthcare context. The task force consisting of rheumatologists from the SIR Epidemiology Unit and a committee with experience on gout identified key health questions to guide a systematic literature review. The target audience includes physicians and health professionals who manage gout in practice, and the target population includes adult patients suspected or diagnosed as having gout. These recommendations were finally rated by an external multi-disciplinary commission.

From a systematic search in databases (Medline, Embase) and grey literature, 8 CPGs were selected and appraised by two independent raters. Combining evidence and statements from these CPGs and clinical expertise, 14 recommendations were developed and graded according to the level of evidence. The statements and potential impact on clinical practice were discussed and assessed.

These revised recommendations are intended to provide guidance for the diagnosis and the treatment of gout and to disseminate the best evidence-based healthcare for this disease.
\end{abstract}

Key words: Clinical practice guideline, recommendations, gout, diagnosis, treatment.

Reumatismo, 2019; 71 (S1): 50-79

\section{INTRODUCTION}

out is a common form of inflammatory

Jarthritis occurring worldwide. Overall prevalence in the Italian general population increased from 6.7 per 1000 inhabitants in 2005 to 9.1 per 1000 inhabitants in 2009, whilst incidence was stable (respectively, 0.93 and 0.95 per 1000 person years) (1).

The pathophysiology of gout is largely known: the chronic deposition of monosodium urate (MSU) crystals in the presence of sustained high serum uric acid (SUA) concentrations triggers the inflammatory response in joints and extra-articular sites $(2,3)$.

Clinical manifestations resulting from MSU deposition include acute arthritis (typically, first affecting the foot or ankle), recurrent and chronic arthritis, tophi, bursitis, urolithiasis and renal disease. Acute arthritis is typically responsive to colchicine, nonsteroidal anti-inflammatory drugs (NSAIDs) or cyclooxygenase-2 inhibitors (COXIBs). Gouty arthritis has impact on disability and health-related quality of life 
(4) and is frequently associated with comorbidities such as hypertension, dyslipidemia, obesity, diabetes mellitus, chronic renal insufficiency, and cardiovascular disease. Furthermore, hyperuricemia was observed to be associated with increased hospitalization risk and healthcare costs in Italy (5).

The availability of effective urate-lowering therapies (ULTs), such as xanthine oxidase inhibitors (XOI), makes gout a potentially curable disease. However, the risk of premature death in these patients remained disturbingly unchanged (6). This runs contrary to what happened with other rheumatic diseases such as rheumatoid arthritis, as observed in the United Kingdom (gout mortality Hazard Ratios 1.10 [95\% CI 1.06 to 1.15 ] in 1999-2006 and 1.09 [95\% CI 1.05 to 1.13 ] in 2007-2014) (7). Since adherence to ULT is a major issue in Italy (8), it has been suggested that optimization of gout treatment is pivotal (9). Clinical practice guidelines (CPGs) are therefore expected to play a key role in achieving optimal management of patients with gout.

\section{THE NEED FOR ITALIAN GUIDELINES}

The most recent Italian Society for Rheumatology (SIR) recommendations focusing on the management of patients with gout were published in 2013 (10) and aimed to update and adapt to the national setting the 2006 European League Against Rheumatism recommendations (EULAR) $(11,12)$. There are many reasons why revised and updated guidelines are now required. First, the prevalence of gout has increased and the growing burden of the disease requires clear and up-to-date CPGs. Secondly, evidence in terms of efficacy and safety for available drugs has accumulated and new treatment options are available. Third, inappropriate ULT prescription both in primary and secondary care appears to be still an issue (13). Finally, several new international guidelines on gout have been published over the last few years (14-21). Thus, SIR has developed recommendations to provide guidance on diagnosis, treat- ment and safety issues in gout, taking into account the Italian practice setting.

\section{Objective}

These guidelines aim to offer revised, evidence-based, and adapted recommendations for the diagnosis and treatment of patients with gout in Italy.

\section{Target patient population}

Adult patients (age $\geq 18$ years) with gout according to the last (22) or prior classification criteria (23) and those suspected of having gout by the treating physician.

\section{Target users}

Attending physicians (general practitioners, rheumatologists, internists, nephrologists, cardiologists, geriatricians) and health professionals who manage patients with gout in primary care, and in hospital and community practice settings. Patients, policy makers and those responsible for commissioning care for patients with gout in the Italian National Health Service (NHS).

\section{What is covered}

These recommendations focus on holistic management of patients with gout across the following domains: diagnosis, treatment and follow-up.

\section{Areas that are not covered}

Recommendations on asymptomatic hyperuricemia, and on hyperuricemia secondary to tumor lysis syndrome, chronic kidney disease, and gene disorders without a diagnosis of gout are not included in this guideline.

\section{MATERIALS AND METHODS}

\section{Approach to guideline development}

De novo guideline development is timeconsuming and requires substantial costs (funds, expertise, and human resources). As several gout guidelines have been published by international scientific associations, a systematic approach based on the framework of the Guidelines International Network Adaptation Working Group (http://www.g-i-n.net), following the work 
of the ADAPTE collaboration $(24,25)$, was adopted to identify, appraise, synthesize, and customize the existing international guidelines to the needs of the Italian healthcare context.

\section{Assembly of the Working Group}

The Working Group consisted of 10 rheumatologists on behalf of the SIR. Six rheumatologists (N.U., I.P., M.M., A.B, A.A., S.P.), and a project coordinator
(C.S.) from the SIR Epidemiology Unit were responsible for the methodology for the development of these recommendations. Three expert clinicians designated by SIR (L.C., R.R., G.F.) were involved in each phase of the guideline development by attending a meeting at the $54^{\text {th }}$ SIR National Meeting (November, 22 ${ }^{\text {nd }}-25^{\text {th }}$ 2017), contributing to e-mail discussions, and participating in web-meetings (February, $13^{\text {th }}$ and $27^{\text {th }} 2018$ ).

Table I - Key questions regarding the overall management of patients with gout. Eleven health question guided the systematic review and the adapted recommendations development.

\begin{tabular}{|c|c|c|}
\hline No. & Health question & No. recommendation \\
\hline \multicolumn{3}{|c|}{ Diagnosis of and assessment of gouty patients } \\
\hline 1. & $\begin{array}{l}\text { When could clinical diagnosis of gout be judged sufficient with or without imaging/laboratory findings? } \\
\text { When is the search for mono-sodium urate crystals in a synovial fluid sample necessary? }\end{array}$ & 1 \\
\hline 2. & $\begin{array}{l}\text { When and which assessments (laboratory and/or imaging) should be performed to screen for co-morbidities } \\
\text { (type } 2 \text { diabetes mellitus, chronic kidney disease, cardiovascular risk) after the diagnosis of gout? }\end{array}$ & $\|$ \\
\hline \multicolumn{3}{|c|}{ Treatment of gout } \\
\hline & \multicolumn{2}{|l|}{ Treatment of acute gout } \\
\hline 3. & When should the treatment of acute gout be started? & III \\
\hline $4 a$. & Which is (are) the first-line treatment(s) in acute gout? & IV \\
\hline \multirow[t]{2}{*}{$4 \mathrm{~b}}$. & $\begin{array}{l}\text { Which is the role of corticosteroids, NSAIDs, colchicine, joint aspiration and/or corticosteroid injection, } \\
\text { IL1 inhibitors? }\end{array}$ & V \\
\hline & \multicolumn{2}{|l|}{ Treatment of hyperuricemia in gout } \\
\hline $5 a$. & Which is (are) the treatment(s) for the prevention of gouty attacks? When should medication(s) be started? & $\mathrm{Vl}$ \\
\hline $5 b$. & Which is the first-line urate-lowering therapy? What dose of allopurinol should be used? & VII \\
\hline \multirow[t]{2}{*}{$5 c}$. & $\begin{array}{l}\text { Which is (are) the second-line urate-lowering treatment(s)? When should a urate-lowering combination } \\
\text { therapy be prescribed? }\end{array}$ & VIIII \\
\hline & \multicolumn{2}{|l|}{ Prevention of gouty attacks } \\
\hline \multirow[t]{2}{*}{6.} & $\begin{array}{l}\text { Which treatment should be used to prevent gouty attacks when the urate-lowering therapy has been started? } \\
\text { When should it be started and how long should it be continued? }\end{array}$ & $\mathrm{IX}$ \\
\hline & \multicolumn{2}{|l|}{ Lifestyle interventions } \\
\hline \multirow[t]{2}{*}{7.} & Which lifestyle interventions should be considered for the management of gouty arthritis? & $X$ \\
\hline & \multicolumn{2}{|l|}{ Management points in special groups } \\
\hline \multirow[t]{2}{*}{8.} & $\begin{array}{l}\text { How may comorbidities influence the choice of treatment and what investigations should be performed } \\
\text { before the treatment is started? }\end{array}$ & $\mathrm{XI}$ \\
\hline & \multicolumn{2}{|l|}{ Co-prescriptions } \\
\hline \multirow[t]{2}{*}{9.} & What drug interactions should be warned about in patients taking medication(s) for gout? & XII \\
\hline & \multicolumn{2}{|l|}{ Management of tophi } \\
\hline 10. & What is (are) the treatment(s) for tophi or severe gout? How should tophi be managed? & XIII \\
\hline \multicolumn{3}{|c|}{ Monitoring of gout and therapeutic targets } \\
\hline 11. & $\begin{array}{l}\text { What target(s) should be aimed at in gout management? What target(s) should be used for the urate-lowering } \\
\text { therapy? What clinical outcome(s) and investigation(s) should be used in monitoring gout? }\end{array}$ & XIV \\
\hline
\end{tabular}




\section{Stakeholder involvement}

The draft of these recommendations was revised and rated by an external multidisciplinary commission of rheumatologists (12), secondary care physicians with specialist experience in internal medicine (1), nephrology (1), geriatrics (1), and clinical pharmacology (1), a general practitioner (1), a health professional (1), and a representative of patients' associations (1) at the invitation of SIR. The recommendations were developed without any input from, or cooperation with, any pharmaceutical company.

\section{Defining the scope}

A comprehensive list of potential management questions to be addressed was developed a priori and defined by consensus. Eleven health questions were identified (Table I) and guided the systematic literature search.

\section{Inclusion and exclusion criteria}

International CPGs and consensus statements with recommendations for gout published in English or Italian between January $1^{\text {st }} 2007$ and June $31^{\text {st }} 2017$ were included. Non-international recommendations were included only if the end-of- search date was after January 1, 2012, or the role of the scientific society was judged relevant. Recommendations on hyperuricemia were included only if they were related to patients with gout.

Reasons for exclusion: study design [randomized controlled trials (RCT) and uncontrolled trials, observational studies, editorials, commentaries, conference abstracts and narrative/systematic reviews]; languages other than English and Italian; poor methodology and reporting; nonoriginal CPGs (i.e. duplication, adaptation or update of previous recommendations) and those which did not answer to the key health questions.

\section{Search strategy}

The strategy was discussed by the members of the SIR Epidemiology Unit and the systematic literature search was performed by N.U. in Medline and Embase databases, combining keywords for gout, drug names, and guidelines and consensus statements (Appendix 1). Furthermore, a grey literature search of rheumatology societies, guideline clearinghouses, crossreferences and a gate-keeper (Google Scholar) was performed. All search results were screened by 2 independent

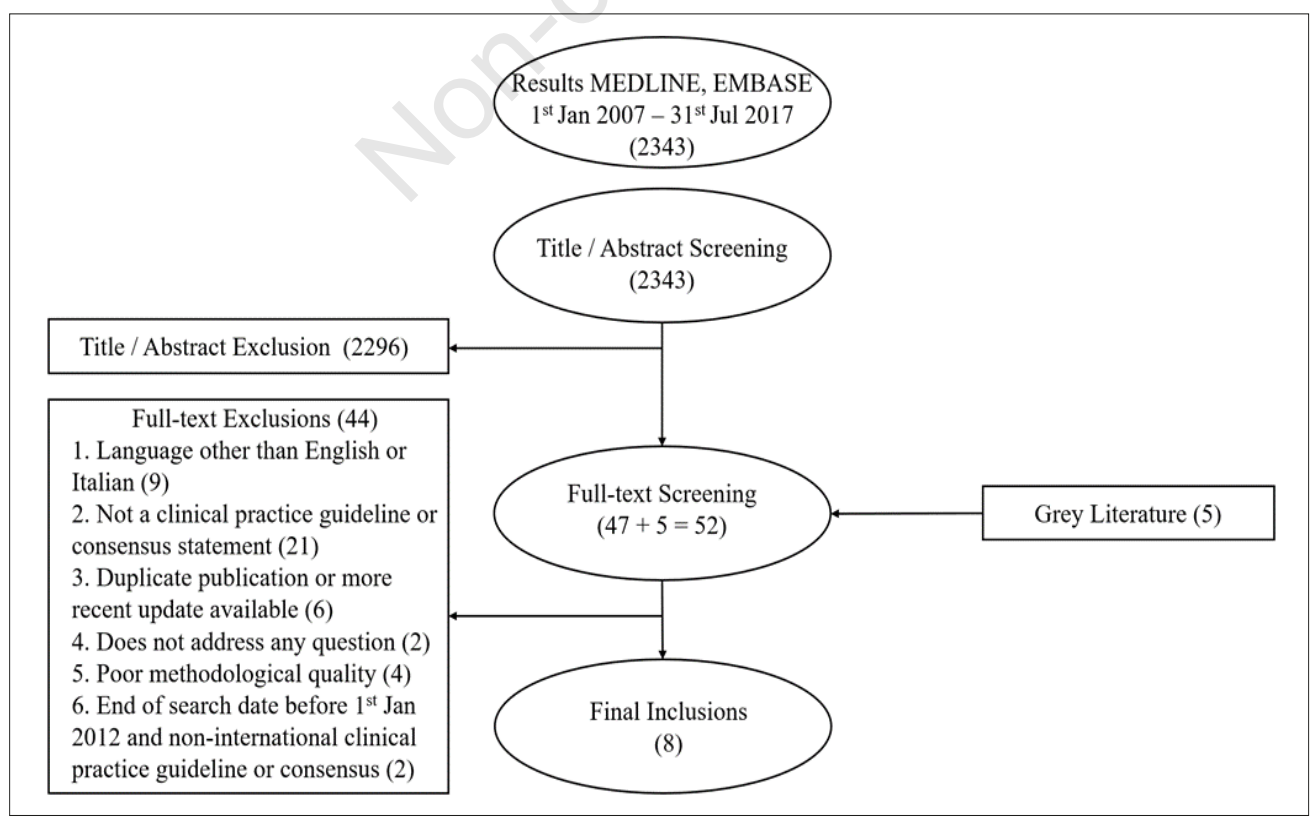

Figure 1 - The steps in the systematic review of guidelines on diagnosis and treatment of gout. 
reviewers (N.U., I.P.) and disagreements were resolved by consensus. A flow chart of the results is shown in Figure 1.

\section{Appraisal of guideline quality}

Guideline quality was assessed by two raters (N.U., I.P.) using the on-line Appraisal of Guidelines Research and Evaluation (AGREE) II instrument (26). The AGREE II is made up of 23 items organized into 6 quality domains: scope and purpose, stakeholder involvement, rigor of development, clarity of presentation, applicability, and editorial independence. Upon completing the 23 items, the criteria considered in the assessment process were used to formulate a score and a single-item overall assessment of the guideline as Recommend (R), Recommended with Provisos ( $\left.\mathrm{R}^{*}\right)$, or Would Not Recommend. The AGREE assessments were not considered as criteria for exclusion.

\section{Level of evidence and strength of recommendation}

Different grading systems for evidence were used across the CPGs. In order to reconcile these differences, each guidelines grading system was revised and the level

Table II - Guidance to categories of evidence and strength of recommendations based on the Oxford Levels of Evidence (27).

\begin{tabular}{|c|l|}
\hline Category & Evidence \\
\hline 1 & $\begin{array}{l}\text { From meta-analysis of randomized controlled trials or from at least } \\
\text { one randomized controlled trial }\end{array}$ \\
\hline 2 & $\begin{array}{l}\text { From at least one controlled study without randomization or from at } \\
\text { least one cohort study }\end{array}$ \\
\hline 3 & From at least one case-control study \\
\hline 4 & From case-series or poor-quality cohort and case-control studies \\
\hline 5 & $\begin{array}{l}\text { From expert committee reports or opinions and/or clinical experience } \\
\text { of respected authorities }\end{array}$ \\
\hline Grade & Strength \\
\hline A & Consistent level 1 studies \\
\hline B & Consistent level 2 or 3 studies or extrapolations ${ }^{\star}$ from level 1 studies \\
\hline C & Level 4 studies or extrapolations ${ }^{\star}$ from level 2 or 3 studies \\
\hline D & $\begin{array}{l}\text { Level } 5 \text { troublingly inconsistent evidence or inconclusive studies at } \\
\text { any level }\end{array}$ \\
\hline
\end{tabular}

${ }^{\star}$ Extrapolations are where data is used in a situation that has potentially clinically important differences from the original study situation. of evidence and strength of recommendation were reported according to the Oxford Levels of Evidence (27) (Table II). In case of disagreements, the rating of the recommendation based on the most updated evidence was considered.

\section{Evidence framework and development of recommendations}

The descriptive characteristics of included CPGs (guideline developer, topic, country, language, publication year, end-of-search date, grading system) and AGREE scores were synthesized in tables (not shown). For each key question, evidence tables containing guideline characteristics, recommendations, AGREE summary scores, and level of evidence and strength of recommendation according to the original grading system were prepared. Each recommendation was developed by endorsement or adaptation and rewording of the existing recommendations. This guidance was prepared in line with the AGREE reporting checklist (28).

\section{External review}

The draft of the recommendations was sent to external reviewers $(n=22)$ for comment and rating. An online survey was performed via Google Forms between March $30^{\text {th }}$ and April 30 2018 and feedback from respondents $(n=19$, response rate $86.4 \%)$ was considered to finalize the recommendations. The results of the external review are provided as supplementary material (Appendix 2).

\section{RESULTS}

\section{Key to understanding these guidelines}

Each recommendation is presented with a level of evidence and strength and is accompanied by a supporting text that is structured as follows:

Recommendation. The final statement of SIR. Summary of guidelines. A synthesis of recommendations made by gout guidelines identified from the systematic review.

Recommendation/supporting evidence. Specific source guidelines that were used for adaptation.

Evidence for recommendation. The guide- 
line panel's discussion of the evidence and clinical experience used to develop the recommendation.

\section{RECOMMENDATIONS}

Eight original CPGs (14-21) were selected and used to accomplish the final set of 14 recommendations (Table III). The evidence linked to recommendation and comments about applicability and potential cost implications are discussed in Appendix 3. An algorithm which summarizes the pathway for the management of patients with gout is shown in Figure 2.

\section{Recommendations for the diagnosis and assessment of gout}

\section{RECOMMENDATION 1}

\section{Diagnosis}

Identification of MSU crystals should be performed for a definite diagnosis of gout; if not possible, a diagnosis of gout can be supported by classical clinical features such as podagra, tophi, rapid response to colchicine $(2, \mathrm{D})$ and/or characteristic imaging findings $(2, \mathrm{~B})$.

(Level 2; Strength B-D)

Table III - The final set of 14 recommendations for the management of gout with respective category of evidence and grade of recommendation.

\begin{tabular}{|c|c|c|c|}
\hline & The final set of 14 recommendations & $\begin{array}{c}\text { Category of } \\
\text { evidence }\end{array}$ & $\begin{array}{c}\text { Grade of } \\
\text { recommendation }\end{array}$ \\
\hline 1 & $\begin{array}{l}\text { Identification of MSU crystals should be performed for a definite diagnosis of gout; if not } \\
\text { possible, a diagnosis of gout can be supported by classical clinical features such as podagra, } \\
\text { tophi, rapid response to colchicine* and/or characteristic imaging findings\$. }\end{array}$ & $2^{*}, 2^{\S}$ & $D^{\star}, B^{\S}$ \\
\hline 2 & $\begin{array}{l}\text { In all patients with gout, the screening for cardiovascular risk factors and co-morbid conditions } \\
\text { (such as cigarette smoking, hypertension, diabetes mellitus, dyslipidemia, obesity and renal } \\
\text { disease) is recommended*. Renal function and comorbidities should be assessed at the time } \\
\text { of diagnosis and then monitored regularly (at least annually) and managed appropriately }\end{array}$ & $3^{\star}, 5^{\S}$ & $C^{*}, D^{\S}$ \\
\hline 3 & $\begin{array}{l}\text { To provide optimal care, attacks should be treated as soon as an attack occurs, ideally } \\
\text { within } 24 \text { hours of symptoms onset }{ }^{\star}, \S \text {. After the first gouty attack, fully informed patients should } \\
\text { be educated to self-medicate at the first warning symptoms and to continue any established } \\
\text { ULT during an attack*. }\end{array}$ & $\begin{array}{l}5^{\star}, 1^{\S} \\
\text { for colchicine }\end{array}$ & $\begin{array}{c}D^{*}, A^{\S} \\
\text { for colchicine }\end{array}$ \\
\hline 4 & $\begin{array}{l}\text { Recommended first-line options for acute flares are colchicine and/or an NSAID or COXIB, } \\
\text { oral corticosteroid, articular aspiration, injection of corticosteroids }{ }^{*}, \text {. The choice of drug(s) } \\
\text { should be discussed with the patient and based on the presence of co-morbidities } \\
\text { (such as impaired renal function), contraindications, the number and type of joint(s) involved }{ }^{\dagger} \text {. } \\
\text { Initial combination therapy is an appropriate option for a severe gouty attack }{ }^{\dagger} \text {. }\end{array}$ & $\begin{array}{l}1^{*} \text { oral, } \\
3^{\S} \text { intra-articular, } \\
\text { intra-muscular, } \\
5^{\dagger}\end{array}$ & $\begin{array}{l}A^{*} \text { oral, } \\
\text { Cs intra-articular, } \\
\text { intra-muscular, } \\
D^{\dagger}\end{array}$ \\
\hline 5 & $\begin{array}{l}\text { In patients with acute gout where response to an appropriate first-line therapy option } \\
\text { is insufficient, the switch to alternative therapy or add-on combination therapy is indicated*. } \\
\text { In non-responders and in patients with contraindications to colchicine, NSAIDs, } \\
\text { COXIBs and corticosteroid (oral and injectable), IL-1 inhibitors may be considereds.t. }\end{array}$ & $\begin{array}{l}5^{\star}, 1^{\S} \\
\text { canakinumab, } \\
4^{\dagger} \text { anakinra }\end{array}$ & $\begin{array}{l}\mathrm{D}^{*}, \mathrm{~A}^{\S} \\
\text { canakinumab, } \\
\mathrm{D}^{\dagger} \text { anakinra }\end{array}$ \\
\hline 6 & $\begin{array}{l}\text { Patients with gout should receive full information and be fully involved from the first presentation } \\
\text { in decision-making concerning the use of ULT as well as to when to commence ULT* The } \\
\text { importance of taking ULT regularly and continually to prevent the return of gout attacks should be } \\
\text { explained*. ULT is indicated close to the time of first diagnosis in all patients with recurrent flares, } \\
\text { tophi, urate arthropathy and/or renal stones, or with a very high SUA level ( }>8.0 \mathrm{mg} / \mathrm{dll} ; 480 \mu \mathrm{mol} / \mathrm{L}) \\
\text { and/or comorbidities (renal impairment, hypertension, ischemic heart disease, heart failure) }\end{array}$ & $2^{*}, 1^{\S}$ & $B^{\star}, A^{\S}$ \\
\hline 7 & $\begin{array}{l}\text { In patients with normal kidney function, allopurinol is the recommended first-line ULT* } \\
\text { Allopurinol starting dosage should be low (no greater than } 100 \mathrm{mg} / \text { day for any patient), } \\
\text { and the dose then increased if required, to reach the SUA target } \$ \text {. }\end{array}$ & $2^{*}, 1^{\S}$ & $\mathrm{B}^{\star}, \mathrm{A}^{\S}$ \\
\hline 8 & $\begin{array}{l}\text { If the SUA target cannot be reached by an appropriate dose of allopurinol or allopurinol cannot } \\
\text { be tolerated, alternatives to consider next include other XOI (febuxostat)*. In patients who are } \\
\text { resistant to, or intolerant of, XOI, uricosuric agents can be used*. In patients who do not achieve } \\
\text { a therapeutic SUA target with optimal doses of monotherapy, a uricosuric agent can be used } \\
\text { in combination with an XOI\$. Uricase as monotherapy should only be considered in patients } \\
\text { with severe gout in whom all other forms of therapy have failed or are contraindicated }\end{array}$ & $1^{*}, 3^{\S}, 2^{\dagger}$ & $A^{*}, C^{\S}, C^{\dagger}$ \\
\hline
\end{tabular}




\begin{tabular}{|c|c|c|c|}
\hline & The final set of 14 recommendations & $\begin{array}{l}\text { Category of } \\
\text { evidence }\end{array}$ & $\begin{array}{l}\text { Grade of } \\
\text { recommendation }\end{array}$ \\
\hline 9 & $\begin{array}{l}\text { Prophylaxis should be initiated with, or just prior to, initiating ULT and the recommended } \\
\text { prophylactic treatment is colchicine*. In patients who cannot tolerate colchicine or if colchicine is } \\
\text { contraindicated, a low-dose NSAID or COXIB can be used as an alternative providing there are } \\
\text { no contraindications or intolerance to NSAIDs or COXIBs*. If colchicine and NSAIDs or COXIBs } \\
\text { are contraindicated, not tolerated, or ineffective, low dose glucocorticoids may be used }{ }^{\S} \text {. }\end{array}$ & $1^{\star}, 5^{\S}$ & $A^{*}, D^{\S}$ \\
\hline 10 & $\begin{array}{l}\text { Modifiable risk factors should be addressed primarily through patient education and support*. } \\
\text { Patients should be advised on a healthy lifestyle including reducing excess body weight, } \\
\text { performing regular exercise, giving up smoking, avoiding excess alcohol, high purine foods } \\
\text { and sugar-sweetened drinks containing fructose }{ }^{\S, *} \text {. }\end{array}$ & $\begin{array}{l}2^{*} \text { for dietary } \\
\text { factors, } 5^{\S}\end{array}$ & $\begin{array}{l}\mathrm{B}^{\star} \text { for dietary } \\
\text { factors, } \mathrm{D}^{\S}\end{array}$ \\
\hline 11 & $\begin{array}{l}\text { In patients with severe renal impairment, for acute gouty attacks, colchicine and NSAIDs } \\
\text { should be avoided. In patients with renal impairment (any grade), allopurinol may be used } \\
\text { with dose adjustment and close monitoring for adverse events and toxicity (e.g., pruritus, } \\
\text { rash, elevated hepatic transaminases)^. If the SUA target cannot be achieved, febuxostat } \\
\text { is an alternative drug that can be used\$s. }\end{array}$ & $4^{\wedge}, 2^{\S}, 2^{\dagger}, 1^{\ddagger}$ & $\mathrm{D}^{\wedge}, \mathrm{B}^{\S}, \mathrm{C}^{\dagger}, \mathrm{A}^{\ddagger}$ \\
\hline 12 & $\begin{array}{l}\text { With patients unable to take medicines orally, acute gouty arthritis attacks may be managed } \\
\text { by intra-articular corticosteroids, intravenous/intramuscular corticosteroids and corticotropin }{ }^{\dagger} \text {. }\end{array}$ & $1^{\star}, 2^{\S}, 4^{\dagger}$ & $A^{*}, B^{\S}, D^{\dagger}$ \\
\hline 13 & $\begin{array}{l}\text { Tophi should be treated medically by achieving a sustained reduction in SUA*. Surgery is only } \\
\text { indicated in selected cases (e.g., nerve compression, mechanical impingement or infection)* }\end{array}$ & $2^{*}$ & $\mathrm{~B}^{*}$ \\
\hline 14 & $\begin{array}{l}\text { The treatment target is SUA levels, eventual absence of gout attacks and resolution of tophi^; } \\
\text { monitoring should include SUA level, frequency of gout attacks and tophi sizes. In all patients } \\
\text { with gout, an SUA }<6.0 \mathrm{mg} / \mathrm{dl}(<360 \mu \mathrm{mol} / \mathrm{L}) \text { should be targeted and maintained life-long }{ }^{\dagger} \text {. } \\
\text { In patients with severe gout, such as those with tophi, chronic arthropathy or frequent attacks, } \\
\text { the target should be an SUA }<5.0 \mathrm{mg} / \mathrm{dl}(<300 \mu \mathrm{mol} / \mathrm{L}) \neq \text {. SUA level }<3.0 \mathrm{mg} / \mathrm{dl}(180 \mu \mathrm{mol} / \mathrm{L}) \text { is not } \\
\text { recommended in the long term due to the possibility of adverse effects that may } \\
\text { be associated with a very low SUA }{ }^{\ddagger} \text {. }\end{array}$ & $2^{\wedge}, 1^{\S}, 1^{\dagger}, 3^{\ddagger}$ & $\mathrm{C}^{\wedge}, \mathrm{B}^{\S}, \mathrm{A}^{\dagger}, \mathrm{D}^{\ddagger}$ \\
\hline
\end{tabular}

MSU, monosodium urate; ULTs, urate-lowering therapies; NSAIDs, nonsteroidal anti-inflammatory drugs; COXIBs, cyclooxygenase-2 inhibitors; IL-1, interleukin-1; SUA, serum uric acid; XOI, xanthine oxidase inhibitors.

Summary of guidelines. The search identified 2 CPGs that addressed the diagnosis of gout (AGREE rating: $\mathrm{R}=2$ ). One guideline recommended performing synovial fluid analysis as a routine working assessment (16), while the other subjugated the search for MSU crystals conditionally to clinical judgment (19).

Recommendation/supporting evidence. 3e Initiative 2014 (16), American College of Physicians (ACP) Diagnosis 2017 (19).

Evidence for recommendation. The panel agreed upon the endorsement of the 3e Initiative 2014 recommendation. The importance of a definite diagnosis of gout was not adequately stressed by the ACP statement (17) and misdiagnosis or delayed diagnosis could lead to inadequate or inappropriate treatment. In this statement, characteristic imaging findings included double-contour sign on ultrasound in symptomatic (ever) joint or bursa and appearance of gout-related erosion (cortical break with sclerotic margin and overhanging edge) on radio- graph of hands and/or feet; the search for urate deposition on dual-energy computed tomography (DECT) is currently limited to referral centers.

\section{RECOMMENDATION 2}

\section{Assessment of co-morbidities}

In all patients with gout, screening for cardiovascular risk factors and co-morbid conditions (such as cigarette smoking, hypertension, diabetes mellitus, dyslipidemia, obesity, and renal disease) is recommended $(3, \mathrm{C})$. Renal function and comorbidities should be assessed at the time of diagnosis and then monitored regularly (at least annually) and managed appropriately (5, D). (Level 3-5; Strength C-D)

Summary of guidelines. The search identified 4 CPGs that addressed the assessment of co-morbidities in gouty patients (AGREE rating: $\mathrm{R}=3, \mathrm{R}^{*}=1$ ). All the guide- 


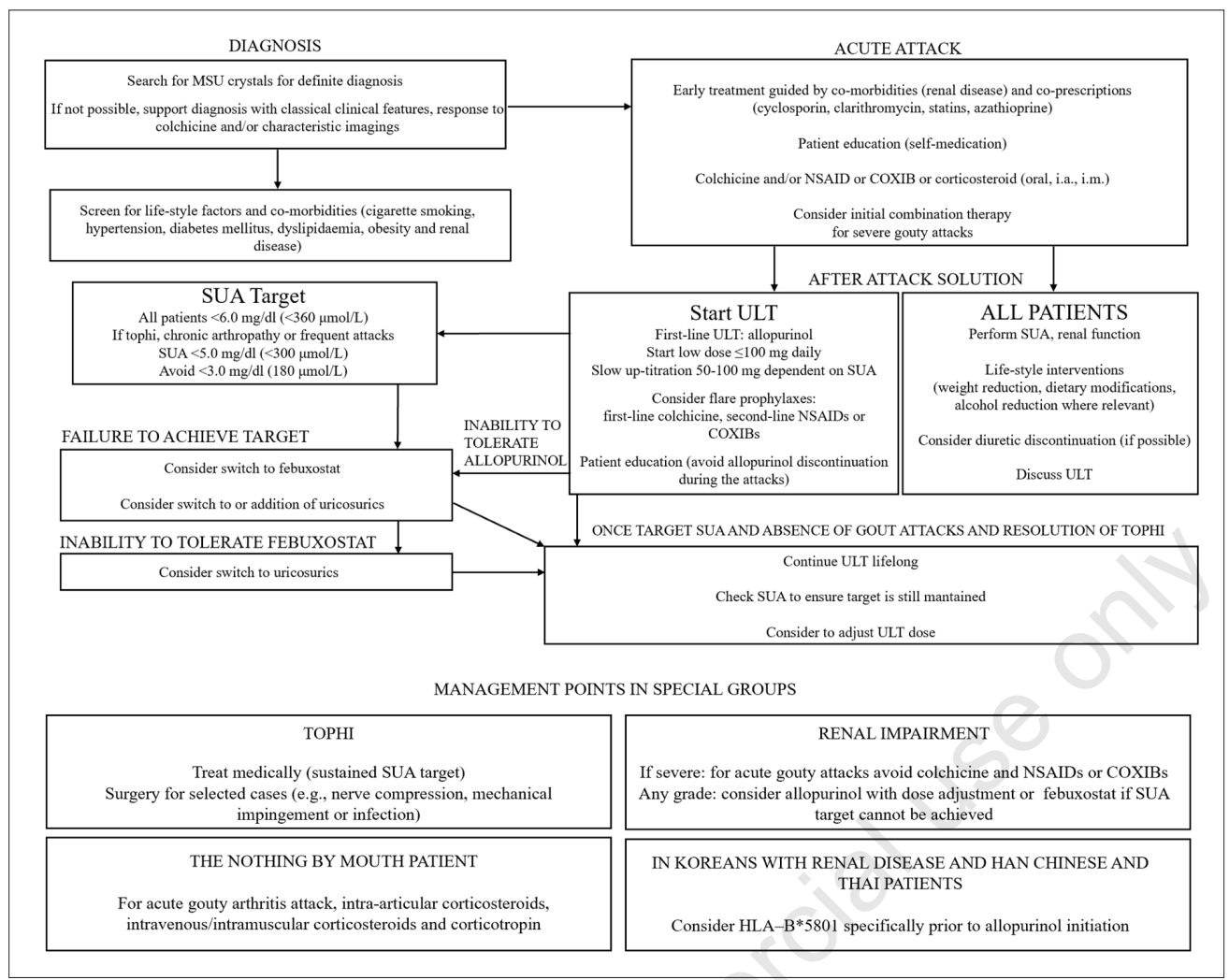

Figure 2 - Diagnosis and treatment of gout according to the revised recommendations of the Italian Society for Rheumatology. MSU, monosodium urate; ULT, urate-lowering therapy; NSAID, nonsteroidal anti-inflammatory drug; COXIB, cyclooxygenase-2 inhibitors; i.a., intraarticular; i.m., intra-muscular.

lines recommended assessing patients with diagnosis of gout for several co-morbidities $(14,16,18,21)$ and gout should be considered a red flag for metabolic syndrome and increased cardiovascular risk (16).

Recommendation/supporting evidence. American College of Rheumatology (ACR) Part I 2012 (14), 3e Initiative 2014 (16), Treat to target (T2T) 2017 (18), British Society for Rheumatology (BSR) 2017 (21).

Evidence for recommendation. The panel agreed that it is appropriate to consider in the clinical evaluation, and if clinically indicated, dietary factors, excessive alcohol intake, metabolic syndrome, modifiable risk factors for coronary artery disease or stroke, serum urate-elevating medications, history of urolithiasis, chronic kidney, glomerular, or interstitial renal disease (e.g., analgesic nephropathy, polycystic kidney disease), and in selected cases, potential genetic or acquired causes of uric acid overproduction (e.g., inborn errors of purine metabolism or psoriasis, myeloproliferative, or lymphoproliferative disease, respectively), and lead intoxication (14).

\section{Recommendations for the treatment of gout}

\section{RECOMMENDATION 3}

\section{Timing for the treatment of acute gout}

To provide optimal care, attacks should be treated as soon as an attack occurs, ideally within 24 hours of symptoms onset (5, D; 1 , A for colchicine). After the first gouty attack, fully informed patients should be educated to self-medicate at the first warning symptoms and to continue any established ULT during an attack (5, D). (Level 1-5; Strength A-D) 
Summary of guidelines. The search identified 4 CPGs that addressed the timing of treatment of gout (AGREE rating: $\mathrm{R}=2$, $\mathrm{R}^{*}=2$ ). All the guidelines recommended treating an acute attack promptly $(15,17$, $18,21)$ and educating the patient to selftreatment $(15,17)$.

Recommendation/supporting evidence. ACR Part II 2012 (15), EULAR 2017 (17), T2T 2017 (18), BSR 2017 (21).

Evidence for recommendation. The panel acknowledged the importance of early treatment as well as the role of patient education in optimizing the management of an acute attack.

\section{RECOMMENDATION 4}

\section{First-line therapy in acute gout}

Recommended first-line options for acute flares are colchicine and/or an NSAID or COXIB, oral corticosteroid, articular aspiration, injection of corticosteroids (1, A oral; 3, C intra-articular, intramuscular). The choice of drug(s) should be discussed with the patient and based on the presence of co-morbidities (such as impaired renal function), contraindications, the number and type of joint(s) involved (5, D). Initial combination therapy is an appropriate option for a severe gouty attack (5, D).

(Level 1-5; Strength A-D)

Summary of guidelines. The search identified 6 CPGs that addressed the choice of the drug for treatment of acute gout (AGREE rating: $\mathrm{R}=4, \mathrm{R}^{*}=2$ ). The choice of treatment should be personalized to the individual patient $(15-18,21)$. Colchicine and/or NSAIDs should be preferred, but also corticosteroids (oral or injective) may be considered $(15-18,20,21)$. One CPG recommended initial combination therapy as an option for selected patients (15).

Recommendation/supporting evidence. ACR Part II 2012 (15), 3e Initiative 2014 (16), EULAR 2017 (17), T2T 2017 (18), ACP Management 2017 (20), BSR 2017 (21).

Evidence for recommendation. The panel agreed that clinicians should use low-dose colchicine (up to $2 \mathrm{mg}$ daily) to treat acute gout (16). On day 1, colchicine at a load- ing dose of $1 \mathrm{mg}$ followed 1 hour later by $0.5 \mathrm{mg}$ (17) or colchicine in doses of 0.5 mg twice or once a day are recommended (21). Full approved dose of NSAIDs or a COXIBs (as an option in patients with gastrointestinal contra-indications or intolerance to NSAIDs) for NHS prescription in acute gout (Italian Medicines Agency AIFA, nota 66) are recommended (15). Patients should continue initial treatment at full dose until the gouty attack has completely resolved (the option to taper the dose in patients with multiple comorbidities/hepatic or renal impairment should be considered) (15). The panel highlighted that gastrointestinal and hematological adverse events should be always considered when prescribing colchicine, as well as cardiovascular, gastrointestinal and renal safety with regard to the prescription of NSAIDs and COXIBs. Patients taking NSAIDs or COXIBs should be co-prescribed a gastro-protective agent $(17,21)$. Joint aspiration and injection of a corticosteroid are highly effective in acute monoarticular gout and may be the preferred treatment in patients with acute illness and co-morbidities (21). For 1-2 large joints, articular aspiration and intra-articular injection of corticosteroids (dose depends on joint size with or without oral treatment) may be considered. A short course of oral corticosteroid (30-35 mg/day of equivalent prednisolone for 3-5 days or prednisone $0.5 \mathrm{mg} / \mathrm{kg}$ per day for 5-10 days at full dose, then stopping, or for 2-5 days at full dose, then tapering for 7-10 days and then stopping) or a single injection of an intramuscular corticosteroid (intramuscular triamcinolone acetonide $60 \mathrm{mg}$ ) then oral prednisone as above is an alternative in patients who are unable to tolerate NSAIDs/ COXIBs/colchicine and in whom intraarticular injection is not feasible $(15,21)$. The panel pointed out that monitoring of diabetes and arterial hypertension should be always considered when prescribing corticosteroids. Systemic (21) and combination (15) therapy is also appropriate for severe gouty attacks, particularly for a polyarticular attack or an attack affecting multiple large joints. Finally, acceptable 
combination therapy approaches include the use of full doses (or, where appropriate, prophylaxis doses) of either:

1) colchicine and NSAIDs or COXIBs,

2) oral corticosteroids and colchicine,

3) intra-articular steroids with all other modalities (15).

The panel agreed that the use of NSAIDs and systemic corticosteroids in combination could arouse concern about synergistic gastrointestinal tract toxicity.

\section{RECOMMENDATION 5}

\section{Second-line and adjunctive therapies in acute gout}

In patients with acute gout where response to an appropriate first-line therapy option is insufficient, the switch to alternative therapy or add-on combination therapy is indicated $(5, \mathrm{D})$. In non-responders and in patients with contraindications to colchicine, NSAIDs, COXIBs and corticosteroid (oral and injectable), IL-1 inhibitors may be considered (1, A canakinumab; 4, D anakinra).

(Level 1-5; Strength A-D)

Summary of guidelines. The search identified 3 CPGs that addressed the choice of second-line, combination and adjunctive therapies in acute gout (AGREE rating: $\left.\mathrm{R}=2, \mathrm{R}^{*}=1\right)$. All the guidelines recommended switching or add on therapy if the first-line monotherapy is insufficient (15, 17, 21). As with the first-line therapy, the choice of drug should be mainly guided by previous treatment(s), safety profile and patient's preference.

Recommendation/supporting evidence. ACR Part II 2012 (15), EULAR 2017 (17), BSR 2017 (21).

Evidence for recommendation. The panel acknowledged that IL-1 blockade by canakinumab (150 mg subcutaneously) or anakinra (100 mg subcutaneously daily for 3 consecutive days) may be considered. Only canakinumab is licensed for use in gout in Europe, while the use of anakinra is currently off-label. However, the panel agreed that the need to effectively lower SUA levels must be emphasized over IL-1 blockade. Moreover, current infection is a major contraindication to the use of IL-1 blockers. Finally, rest, elevation and exposure in a cool environment of affected joints as well as bed-cages and ice-packs may be effective adjuncts to the management of the acute attack.

\section{RECOMMENDATION 6}

\section{Timing for the treatment} of hyperuricemia in gout

Patients with gout should receive full information and be fully involved from the first presentation in decision-making concerning the use of ULT as well as to when to commence ULT $(2, \mathrm{~B})$. The importance of taking ULT regularly and continually to prevent the recurrence of gout attacks should be explained (2, B). ULT is indicated close to the time of first diagnosis in all patients with recurrent flares, tophi, urate arthropathy and/or renal stones, or with a very high SUA level $(>8.0 \mathrm{mg} / \mathrm{dL}$; $480 \mu \mathrm{mol} / \mathrm{L}$ ) and/or comorbidities (renal impairment, hypertension, ischemic heart disease, heart failure) $(1, \mathrm{~A})$.

(Level 1-5; Strength A-D)

Summary of guidelines. The search identified 2 CPGs that addressed the timing of treatment of hyperuricemia in gout (AGREE rating: $\mathrm{R}=1, \mathrm{R} *=1$ ). The two CPGs recommended that ULT should be always considered in all patients with a diagnosis of gout, particularly for selected patients $(17,21)$. Only one CPG recommended against initiating long-term ULT in most patients after a first gout attack or in patients with infrequent attacks (20).

Recommendation/supporting evidence. EULAR 2017 (17), BSR 2017 (21).

Evidence for recommendation. The panel agreed that ULT should be advised in patients with the following characteristics: recurrent attacks ( $\geq 2$ attacks in 12 months), joint damage, diuretic therapy use, and primary gout starting at a young age ( $<40$ years) $(17,21)$. All ULTs should be started at a low dose and then titrated upwards until the SUA target is reached $(14,16,17,21)$. Clinicians should ensure 
that patients are aware of the importance of continuing any established ULT during an attack (14). Patients should be supported during the process of lowering their SUA levels as it can cause an increase in gout flares during this time (21). Initiation is best delayed until inflammation has settled as ULT is better discussed when the patient is not in pain (21).

\section{RECOMMENDATION 7}

\section{First-line ULT in gout}

In patients with normal kidney function, allopurinol is the recommended first-line ULT (2, B). Allopurinol starting dosage should be low (no greater than $100 \mathrm{mg} /$ day for any patient), and the dose then increased if required, to reach SUA target $(1, \mathrm{~A})$.

(Level 1-2; Strength A-B)

Summary of guidelines. The search identified 4 CPGs that addressed the choice of the first-line ULT (AGREE rating: $\mathrm{R}=3$, $\mathrm{R}^{*}=1$ ). There is a strong consensus that allopurinol should be the first-line ULT and the choice of allopurinol over febuxostat was explicitly recommended in three CPGs $(16,17,21)$, while one CPG recommended either allopurinol or febuxostat (14).

Recommendation/supporting evidence. ACR Part I 2012 (14), 3e Initiative (16), EULAR 2017 (17), BSR 2017 (21).

Evidence for recommendation. The panel agreed that allopurinol should be the firstline therapy within an up-titration strategy. The dose of allopurinol should be increased by $100 \mathrm{mg}$ every $2-4$ weeks if required, to a maximum dose of $600-800 \mathrm{mg}$. Until studies performing a direct comparison between allopurinol and febuxostat (and other ULTs) in line with the recommended up-titration regimens are available, allopurinol should be the first option. Moreover, the use of allopurinol and dose-escalation strategy are cost-effective $(29,30)$. Finally, febuxostat is approved by the Italian NHS for prescription in gout when SUA levels or disease are not controlled by allopurinol or when allopurinol cannot be tolerated (AIFA, nota 91).

\section{RECOMMENDATION 8}

\section{Second-line and combination ULTS in gout}

If the SUA target cannot be reached by an appropriate dose of allopurinol or allopurinol cannot be tolerated, alternatives to consider next include other XOI (febuxostat) $(1, A)$. In patients who are resistant to, or intolerant of, XOI, uricosuric agents can be used $(1, A)$. In patients who do not achieve a therapeutic SUA target with optimal doses of monotherapy, a uricosuric agent can be used in combination with a XOI (3, C). Uricase as monotherapy should only be considered in patients with severe gout in whom all other forms of therapy have failed or are contraindicated $(2, \mathrm{C})$.

(Level 1-3; Strength A-C)

Summary of guidelines. The search identified 4 CPGs that addressed the choice of ULT following the first-line regimen (AGREE rating: $\mathrm{R}=3, \mathrm{R}^{*}=1$ ). Three $\mathrm{CPGs}$ recommended either XOI or a uricosuric or a combination as second-line ULT $(14,16$, 17) and one CPG recommended the use of an alternative XOI whereas uricosurics and combinations were recommended as thirdline regimens (21). The only two CPGs which addressed uricase recommended its use as the last line therapy $(16,17)$.

Recommendation/supporting evidence. ACR Part I 2012 (14), 3e Initiative (16), EULAR 2017 (17), BSR 2017 (21).

Evidence for recommendation. The panel agreed that febuxostat should be a secondline ULT at a dose of $80 \mathrm{mg}$ daily and, if necessary, increased after 4 weeks to $120 \mathrm{mg}$ daily, to achieve the therapeutic target (21). The cost-effective use of febuxostat as second-line ULT is supported by health economic studies $(29,30-32)$. Among uricosurics, lesinurad $(200 \mathrm{mg} /$ day in association with a XOI) is currently the only uricosuric available for gout in Italy (33), while probenecid and benzbromarone are not available in Italy, and the use of sulfinpyrazone in gout is offlabel. Probenecid (500-2000 mg/day) and sulfinpyrazone (200-800 mg/day) may be used in patients with normal or mildly im- 
paired renal function, and benzbromarone (50-200 mg/day) in patients with mild to moderate renal insufficiency $(14,21)$. History of urolithiasis and elevated urine uric acid contraindicate uricosuric ULTs (14). Other agents with clinically significant uricosuric effects, such as losartan and fenofibrate should not be used as a primary ULT but they may be considered as components of a comprehensive ULT strategy where treatment of hypertension or dyslipidemia is required, respectively (17, 21). Calcium channel blockers and statins may be also considered for hypertension and for hyperlipidemia, respectively (17, 21). Vitamin C supplements (500-1500 $\mathrm{mg}$ daily) also have a weak uricosuric effect (21). Finally, urine alkalinization (e.g., with potassium citrate $60 \mathrm{mEq} /$ day) with monitoring of urine $\mathrm{pH}$ may be considered, in addition to increased fluid intake, as a risk management strategy for urolithiasis in recurrent stone formers (14, $21)$. With regards to uricases, although high quality evidence for reduction of SUA levels is available, pegloticase is not commercially available in Italy; rasburicase was successfully used in case series of patients with severe gout, but its use is currently off-label in Italy.

\section{RECOMMENDATION 9}

\section{Flare prophylaxis}

Prophylaxis should be initiated with, or just prior to initiating, ULT and the recommended prophylactic treatment is colchicine $(1, \mathrm{~A})$. In patients who cannot tolerate colchicine or if colchicine is contraindicated, a low-dose NSAID or COXIB can be used as an alternative providing there are no contraindications or intolerance to NSAIDs or COXIBs $(1, \mathrm{~A})$. If colchicine, NSAIDs and COXIBs are contraindicated, not tolerated, or ineffective, low dose glucocorticoids may be used (5, D).

(Level 1-5; Strength A-D)

Summary of guidelines. The search identified 6 CPGs that addressed the prophylaxis of gout flare when ULT is started (AGREE rating: $\mathrm{R}=4, \mathrm{R}^{*}=2$ ). There is consensus across the CPGs about the need for flare prophylaxis (15-21). Three CPGs recommended colchicine as first-line and NSAIDs (or COXIBs) as second-line (16, $17,21)$ treatments and one CPG recommended either colchicine or NSAIDs as first-line therapy (15). Low dose glucocorticoids were not recommended as first-line drug by four CPGs $(15-17,21)$. The choice of drug for prophylaxis was not addressed by two CPGs $(18,20)$.

Recommendation/supporting evidence. ACR Part II 2012 (15), 3e Initiative 2014 (16), EULAR 2017 (17), T2T 2017 (18), ACP Management 2017 (20), BSR 2017 (21).

Evidence for recommendation. The panel agreed that the prophylactic dose of colchicine should be $0.5-1 \mathrm{mg} / \mathrm{day}$, and it should be reduced in patients with renal impairment. Low-dose NSAIDs (e.g. naproxen $250 \mathrm{mg}$ twice daily) are suggested with proton pump inhibitor (where indicated) $(15,17,21)$. The suggested low dose glucocorticoids are prednisone $\leq 10 \mathrm{mg} /$ day (15). Prophylaxis is recommended during at least the first 6 months of ULT. A 3-6 month duration after achieving target SUA (3 months if no tophi detected on physical exam, 6 months if one or more tophi detected on physical exam) should be considered (15).

\section{RECOMMENDATION 10}

\section{Lifestyle interventions}

Modifiable risk factors should be addressed primarily through patient education and support (2, B). Patients should be advised on a healthy lifestyle including reducing excess body weight, performing regular exercise, giving up smoking, avoiding excess alcohol, high purine foods, and sugarsweetened drinks containing fructose (5, D; 2, B for dietary factors).

(Level 2-5; Strength B-D)

Summary of guidelines. The search identified 5 CPGs that addressed non-pharmacologic interventions related to lifestyle (AGREE rating: $\mathrm{R}=4, \mathrm{R}^{*}=1$ ). All the $\mathrm{CPGs}$ agreed that information on lifestyle is advisable in patients with gout $(14-17,21)$. 
Recommendation/supporting evidence. ACR Part I 2012 (14), ACR Part II 2012 (15), 3e Initiative 2014 (16), EULAR 2017 (17), BSR 2017 (21).

Evidence for recommendation. The panel agreed that a healthy diet (for cardiac health and control of co-morbidities such as obesity, metabolic syndrome, diabetes, dyslipidemia, and hypertension), low in fat and added sugars, should be encouraged $(14,21)$. Sugar-sweetened soft drinks containing fructose, high purine foods (organ meats, e.g. sweetbread, liver or kidney), excessive intake of alcoholic drinks (defined as more than 2 servings per day for a male and 1 serving per day for a female - particularly beer, but also wine and spirits), any alcohol use during periods of frequent gout attacks, or advanced gout under poor control should be avoided $(14,21)$. Serving sizes of beef, lamb, pork, seafood with high purine content (e.g. sardines, shellfish), naturally sweet fruit juices, desserts, table sugar and salt, sauces, and gravies should be limited (14). Inclusion of skimmed milk and/or low-fat yoghurt, soy beans and vegetable sources of protein, fiber and cherries in the diet should be encouraged $(14,21)$. Exercise to achieve physical fitness and giving up smoking, and, in overweight patients, dietary modification to achieve a gradual reduction in body weight that promotes general health and subsequent maintenance should be encouraged $(14,21)$.

\section{RECOMMENDATION 11}

\section{Management points in special groups}

In patients with severe renal impairment, colchicine and NSAIDs should be avoided for acute gouty attacks. In patients with renal impairment (any grade), allopurinol may be used with dose adjustment and close monitoring for adverse events and toxicity (e.g., pruritus, rash, elevated hepatic transaminases) $(4, D)$. If the SUA target cannot be achieved, febuxostat $(2, \mathrm{~B})$ is an alternative drug that can be used.

With patients unable to take medicines orally, acute gouty arthritis attack may be managed by intra-articular corticosteroids, intravenous/intramuscular corticosteroids and corticotropin $(2, \mathrm{C})$.

In subpopulations at higher risk of severe allopurinol hypersensitivity reaction (e.g., Koreans with stage 3 chronic kidney disease or worse, and Han Chinese and Thai irrespective of renal function) HLAB*5801 should be considered specifically prior to initiation $(1, \mathrm{~A})$.

(Level 1-4; Strength A-D)

Summary of guidelines. The search identified 6 CPGs that addressed special groups of patients and the influence of co-morbidities (AGREE rating: $\mathrm{R}=4, \mathrm{R}^{*}=2$ ). All the CPGs acknowledged that comorbidities associated with gout may influence therapy and outcomes and should be assessed regularly and subject to ongoing management. Careful drug prescription is recommended in co-morbid patients, especially those with renal impairment (14-18, 21). One CPG highlighted a special warning towards severe adverse reactions to allopurinol in specific populations (14) and one CPG considered the management of gout in the patients unable to take medicines orally (15).

Recommendation/supporting evidence. ACR Part I 2012 (14), ACR Part II 2012 (15), 3e Initiative 2014 (16), EULAR 2017 (17), T2T 2017 (18), BSR 2017 (21).

Evidence for recommendation. The panel agreed that in patients with renal impairment, the recommended dose of colchicine for prophylactic treatment $(0.5-1 \mathrm{mg} /$ day $)$ should be reduced and patients and physicians should be aware of potential neurotoxicity and/or muscular toxicity (17). Allopurinol dose should be adjusted to creatinine clearance and started at a low daily dose (50-100 mg), then up-titrated with small increments $(50 \mathrm{mg})$ to achieve the SUA target. The maximum dose should be lower and may be raised above $300 \mathrm{mg}$ daily as long as it is accompanied by adequate patient education and monitoring for drug toxicity $(16,17,21)$. Febuxostat can be used without dose adjustment, except in patients with estimated glomerular filtration rate $<30 \mathrm{~mL} / \mathrm{min}$ (17). With patients unable to take medicines orally, acute 
gouty arthritis attack may be managed by intra-articular corticosteroids (dose varies by joint size), intravenous/intramuscular corticosteroids (initial methylprednisolone $0.5-2 \mathrm{mg} / \mathrm{kg}$, then it can be repeated and the subsequent dose will be determined on the basis of the initial response) (15); finally, corticotropin by injection might be considered (initial ACTH 25-40 IU, equal to tetracosactide $0.25-0.40 \mathrm{mg}$, then repeated and subsequent doses based on response) $(15,31)$.

\section{RECOMMENDATION 12}

\section{Co-prescriptions}

Co-prescription of colchicine with strong P-glycoprotein and/or CYP3A4 inhibitors, such as cyclosporin or clarithromycin, should be avoided $(1, A)$. In cases of renal impairment or statin treatment, patients and physicians should be aware of potential neurotoxicity and/or muscular toxicity with prophylactic colchicine (2, B). If loop or thiazide diuretics are being used to treat hypertension rather than heart failure, substitution of the diuretic if possible and an alternative antihypertensive agent can be considered $(4, \mathrm{D})$.

(Level 1-4; Strength A-D)

Summary of guidelines. The search identified 2 CPGs that explicitly addressed the choice of co-prescriptions in gout therapy (AGREE rating: $\left.\mathrm{R}=1, \mathrm{R}^{*}=1\right)(17,21)$. Another CPG included warnings about the combination of selected drugs for gout treatment (14).

Recommendation/supporting evidence. EULAR 2017 (17), BSR 2017 (21).

Evidence for recommendation. The panel agreed upon the importance of drug label information and, in particular, that the co-prescription of allopurinol with mercaptopurine/azathioprine is not recommended and when the combination cannot be avoided the dosage of mercaptopurine/ azathioprine should be reduced (approximately one-fourth of the usual dose), since the metabolism of mercaptopurine/azathioprine is known to be inhibited (34); febuxostat should not be used in combination with other xanthine oxidase substrate drugs, such as mercaptopurine/azathioprine and allopurinol since drug interaction studies have not been performed (32); pharmacologic oral ULTs should be discontinued during the course of pegloticase therapy to avoid masking the loss of a pegloticase serum urate-lowering effect associated with an increased risk of pegloticase infusion reactions (35).

\section{RECOMMENDATION 13}

\section{Treatment of tophi}

Tophi should be treated medically by achieving a sustained reduction in SUA (2, B). Surgery is only indicated in selected cases (e.g., nerve compression, mechanical impingement or infection) (2, B).

(Level 1-2; Strength A-B)

Summary of guidelines. The search identified 3 CPGs that addressed the management of severe gout with development of tophi (AGREE rating: $\mathrm{R}=2, \mathrm{R}^{*}=1$ ). All three CPGs agreed that pharmacologic therapy should be the first-line treatment $(14,16,17)$, while surgical approach was addressed only by one CPG (16). Another CPG reported special management points for severe refractory tophaceous gout (21). Recommendation/supporting evidence. ACR Part I 2012 (14), 3e Initiative (16), EULAR 2017 (17).

Evidence for recommendation. The panel agreed that pharmacologic treatment should be preferred over surgery.

\section{Recommendations for monitoring of gout}

\section{RECOMMENDATION 14}

\section{Therapeutic targets}

The treatment target is SUA levels, eventual absence of gout attacks and resolution of tophi $(2, \mathrm{C})$; monitoring should include SUA level, frequency of gout attacks and tophi size $(1, \mathrm{~B})$. In all patients with gout, a SUA $<6.0 \mathrm{mg} / \mathrm{dl}(<360 \mu \mathrm{mol} / \mathrm{L})$ should be targeted and maintained life-long $(1, \mathrm{~A})$. In patients with severe gout, such as those 
with tophi, chronic arthropathy or frequent attacks, the target should be a SUA $<5.0$ $\mathrm{mg} / \mathrm{dl}(<300 \mu \mathrm{mol} / \mathrm{L})(3, \mathrm{D})$. SUA level $<3.0 \mathrm{mg} / \mathrm{dl}(180 \mu \mathrm{mol} / \mathrm{L})$ is not recommended in the long term due to the possibility of adverse effects that may be associated with a very low SUA $(3, \mathrm{D})$.

(Level 1-3; Strength A-D)

Summary of guidelines. The search identified 5 CPGs that addressed the therapeutic targets in gout (AGREE rating: $\mathrm{R}=3$, $\mathrm{R}^{*}=2$ ). All the CPGs recommended SUA levels both as therapeutic target and for monitoring. Four CPGs recommended SUA level target $<6.0 \mathrm{mg} / \mathrm{dl}$ (14-18) and one CPG recommended the more stringent target $<5.0 \mathrm{mg} / \mathrm{dl}$ (21). Three CPGs suggested other clinical outcomes (symptoms related to gout and tophi) further to SUA levels $(14,16,21)$.

Recommendation/supporting evidence. ACR Part I 2012 (14), 3e Initiative (16), EULAR 2017 (17), T2T 2017 (18), BSR 2017 (21). Evidence for recommendation. The panel agreed that the levels of SUA should be measured regularly (every 2-4 weeks during ULT titration, including continuing measurements every 6 months once the serum urate target is achieved) and ULT should be adjusted to attain the target (14). After some years of successful treatment, in patients with severe gout when tophi have resolved and the patient remains free of symptoms, the dose of ULT may be adjusted to maintain the SUA at or below a target of $6.0 \mathrm{mg} / \mathrm{dl}(360 \mu \mathrm{mol} / \mathrm{L})$ $(17,18,21)$. Urinary uric acid should be monitored in the case of uricosuric ULT (14).

\section{Summary of changes to the revised recommendations}

These revised recommendations differ in some aspects from the 2013 SIR guidelines for gout (10).

First, the methodology of the ADAPTE collaboration was adopted and multiple CPGs endorsed by relevant scientific societies were used to produce a comprehensive CPG adapted to the Italian setting.

Secondly, new recommendations were added with regards to diagnosis and follow-up. An entire recommendation was addressed to diagnosis given that the optimal management of gouty arthritis in clinical practice was judged to start from the proper identification of patients suitable for treatment. With regards to the therapeutic targets, a SUA target $<6 \mathrm{mg} /$ dl was confirmed, and new targets $<5 \mathrm{mg} /$ dl for patients with severe gout and $>3$ $\mathrm{mg} / \mathrm{dl}$ for all patients were recommended on the basis of growing evidence and widespread international expert opinion $(36,37)$.

Then, the strategy of personalized therapy according to disease phenotype and the presence of co-morbidities was maintained. The importance of co-morbidity in terms of screening at diagnosis of gout and subsequent monitoring was highlighted since co-morbidities are major determinants of choice of therapy, prognosis and life expectancy in these patients (38) and a multidisciplinary approach should be pursued (39). The mainstay of treatment of the acute attack with colchicine (low doses) and/or NSAIDs or COXIBs was unchanged and the timing of treatment, the choice of the first-line and the second-line treatment, including combination and adjunctive therapies, were defined. Therein, updates on IL-1 blockade in gout were added and the limitations of its role discussed. Allopurinol was confirmed as an efficacious and cost-effective first-line ULT in gout $(29,30)$. Moreover, lower total and cardiovascular mortalities were observed in patients treated with allopurinol compared to febuxostat (40). Despite the longstanding absence of uricosurics other than off-label prescriptions in Italy, general recommendations on uricosuric ULTs were preserved in these guidelines since lesinurad, a selective uric acid reabsorption inhibitor, was approved for NHS prescription in gout. However, new evidence is awaited during the postmarketing phase in order to issue specific recommendations. The choice and timing of ULT commencement is still a controversial issue and recommendations are largely expert opinion based. Most of the 
CPGs agreed upon starting ULT in all patients with a definite diagnosis of gout, whereas the ACP alone recommended against this. The panel of these revised guidelines agreed with the consensus statement of the Gout, Hyperuricemia and Crystal-Associated Disease Network which opposed ACP statement due to concerns about potential undertreatment of gouty patients (41).

Pharmacologic therapies are considered the mainstay of treatment of gout, but nonpharmacologic interventions have still a role. The importance of patients' education and lifestyle interventions was confirmed, although high-quality evidence is still lacking and recommendations remained generic and chiefly related to co-morbidities. In these guidelines, drug safety was particularly emphasized given that adverse reactions, although uncommon, could be highly serious in specific subpopulations such as patients known for chronic kidney disease.

These revised guidelines have some limitations. Firstly, the last update of the literature search is conditional to the end-ofsearch date of the CPGs included (March 2016) (20) and the following evidence was not considered. Furthermore, health economic evaluations are scarce due to the paucity of studies in literature, but the available evidence was taken into account throughout these guidelines.

\section{Plans for updating}

These recommendations were endorsed by SIR as guides only and they do not substitute the individual clinicians' judgment since they may not apply to all patients and to all clinical situations. The SIR plans to review and update these recommendations in the future to determine if they remain current and to take into account future treatments or advances in the management of gout.

Disclosure statements: N.U. reports a grant from SIR and honoraria for consultations from Mundipharma Pharmaceuticals outside the submitted work; I.P. reports a grant from SIR and honoraria due to ad- visory board from Abbvie; R.R. reports to be involved in an EULAR task force to update the recommendations for management of hand osteoarthritis; M.M. reports a grant from SIR, honoraria due to advisory boards from Celgene and Sanofi and other from Lilly, Alfa Wassermann, Merck Sharp \& Dohme outside the submitted work; A.B. reports honoraria due to advisory board from GlaxoSmithKline outside the submitted work; S.P. reports a grant from SIR and other related to advisory boards from Abbvie, Celgene, Janssen, Biogen, Bristol-Myers Squibb, Sanofi, and other related to scientific advice from Baldacci, and Chiesi outside the submitted work; A.A. reports a grant from SIR; C. A. S. reports consultancy for Astra-Zeneca. All other authors have declared no conflicts of interest.

Author Contributions: All authors were involved in drafting the article or revising it critically for important intellectual content, and all authors approved the final version to be published. Conception and design: C.A.S., N.U., I.P., M.M., A.B., S.P., A.A. Systematic review search and CPGs rating: N.U., I.P.. Analysis and discussion of the recommendations: N.U., I.P., R.R., L.C., G.F., M.M., A.B., S.P., A.A., C.A.S..

Funding: These recommendations matched no specific funding from any bodies in the public, commercial sectors or non-profit organization. Non-economic support, such as meeting rooms and secretariat services, was provided by SIR to carry out the work described in this manuscript.

Acknowledgements: The Authors acknowledged all the external reviewers (in alphabetical order those who gave consent for publication): Atteritano M., Bartoletti P.L., Bellasi A., Borghi C., Caprioli M., Ceccarelli F., Cimmino M.A., D'Alessandro G., Desideri G., Dritan Q., Govoni M., Montecucco M., Santo L., Tirri E., Tonolo S., Trifirò E., Venturino F. We are grateful to Solazzo T. as part of SIR secretariat for administrative support. 


\section{APPENDIX 1 \\ KEYWORDS FOR THE SYSTEMATIC LITERATURE SEARCH}

\section{Medline via Pubmed}

("Gout" [MeSH Terms] OR "Gout" [Text Word] OR "Gouts" [Text Word] OR "Gouty arthritis" [Text Word] OR "tophus" [Text Word] OR "tophi" [Text Word] OR "Gout suppressants" [MeSH Terms] OR "Gout suppressants" [Text Word] OR "Antigout agents" [Text Word] OR "Antihyperuricemics" [Text Word] OR "Xanthine oxidase inhibitor" [Text Word] OR "Uricosuric agents" [MeSH Terms] OR "Uricosuric agents" [Text Word] OR "Urate oxidase" [MeSH Terms] OR "Urate oxidase" [Text Word] OR "Uricase" [Text Word] OR "Allopurinol" [MeSH Terms] OR "Allopurinol" [Text Word] OR "Febuxostat" [MeSH Terms] OR "Febuxostat" [Text Word] OR "Probenecid" [MeSH Terms] OR "Probenecid" [Text Word] OR "Benzbromarone" [MeSH Terms] OR "Benzbromarone" [Text Word] OR "Pegloticase" [Text Word] OR "Colchicine" [MeSH Terms] OR "Colchicine" [Text Word]) AND ("Practice Guideline" [Publication Type] OR "Practice Guidelines As Topic" [MeSH Terms] OR "Practice Guideline" [Text Word] OR "Practice Guidelines" [Text Word] OR "Guideline" [Publication Type] OR "Guidelines As Topic" [MeSH Terms] OR "Guideline" [Text Word] OR "Guidelines" [Text Word] OR
"Consensus Development Conference" [Publication Type] OR "Consensus" [MeSH Terms] OR "Consensus" [Text Word] OR "Recommendation" [Text Word] OR "Recommendations" [Text Word] OR "Best Practice" [Text Word] OR "Best Practices" [Text Word]) AND (“2007/01/01” [PDAT] : “2017/12/31” [PDAT])

\section{Embase}

('gout'/exp OR 'gout' OR 'arthragra'/exp OR 'arthraga' OR 'arthritis urica'/exp OR 'arthritis urica' OR 'arthritis, gouty'/exp OR 'arthritis, gouty' OR 'gouty arthritis'/exp OR 'gouty arthritis' OR 'gouty attack/exp' OR 'gouty attack' OR 'urate inflammation/exp' OR 'urate inflammation' OR 'uric arthritis/exp' OR 'uric arthritis' OR 'cheiragra'/ exp OR 'cheiragra' OR 'chiragra'/exp OR 'chiragra' OR 'antigout agent'/exp OR 'antigout agent' OR 'antigout agents'/exp OR 'antigout agents' OR 'gout suppressants'/exp OR 'gout suppressants' OR 'allopurinol'/ exp or 'allopurinol' OR 'febuxostat'/exp OR 'febuxostat' OR 'uricosuric agent'/exp OR 'uricosuric agent' OR 'uricosuric agents'/ exp OR 'uricosuric agents' OR 'uricosuric'/ exp OR 'uricosuric' OR 'uricosurics'/exp OR 'uricosurics' OR 'uricosuricum'/exp
OR 'uricosuricum' OR 'benzbromarone'/ exp OR 'benzbromarone' OR 'probenecid'/ exp OR 'probenecid' OR 'urate oxidase'/ exp OR 'urate oxidase' OR 'uricase'/exp OR 'uricase' OR 'pegloticase'/exp OR 'pegloticase' OR 'colchicine'/exp OR 'colchicine') AND ('practice guideline'/exp OR 'practice guideline' OR 'practice guidelines'/exp OR 'practice guidelines' OR 'clinical practice guideline'/exp OR 'clinical practice guideline' OR 'clinical practice guidelines'/exp OR ‘clinical practice guidelines' OR ‘clinical practice guidelines as topic'/exp OR 'clinical practice guidelines as topic' OR 'guideline'/ exp OR 'guideline' OR 'guidelines'/exp OR 'guidelines' OR 'guidelines as topic'/exp OR 'guidelines as topic' OR 'consensus development'/exp OR 'consensus development' OR 'consensus development conference'/exp OR 'consensus development conference' OR 'consensus development conferences'/exp OR 'consensus development conferences' OR 'consensus development conferences as topic'/exp OR 'consensus development conferences as topic' OR 'consensus'/exp OR 'consensus' OR 'recommendation' OR 'recommendations') AND [2007-2017]/py AND [embase]/lim NOT [medline]/lim

\section{APPENDIX 2 \\ LEVEL OF AGREEMENT (SCORE 1-10) FOR EACH REVISED RECOMMENDATION RATED BY THE MULTIDISCIPLINARY EXTERNAL COMMISSION (N=19). A MINIMUM SCORE $\geq 7$ WAS USED A PRIORI TO CONSIDER EACH RECOMMENDATION ACCEPTABLE FOR CLINICAL PRACTICE PURPOSES}

\begin{tabular}{|c|c|}
\hline $\mathbf{N}^{\circ}$ Item & Level of agreement, median (range) \\
\hline 1 & $8(6-10)$ \\
\hline 2 & $10(6-10)$ \\
\hline 3 & $9(7-10)$ \\
\hline 4 & $9(8-10)$ \\
\hline 5 & $8(6-10)$ \\
\hline 6 & $9(6-10)$ \\
\hline 7 & $10(6-10)$ \\
\hline 8 & $9(7-10)$ \\
\hline 9 & $9(6-10)$ \\
\hline 10 & $10(7-10)$ \\
\hline 11 & $8(5-10)$ \\
\hline 12 & $9(4-10)$ \\
\hline 13 & $10(7-10)$ \\
\hline 14 & $10(7-10)$ \\
\hline
\end{tabular}




\section{APPENDIX 3}

\section{SUMMARY OF EVIDENCE LINKED TO RECOMMENDATIONS AND COMMENTS ABOUT BENEFITS, HARMFUL EFFECTS AND BARRIERS TO IMPLEMENTATION RELATED TO RECOMMENDATIONS}

\section{Recommendation 1: \\ Diagnosis}

Summary of evidence linked to recommendation. The 3e Initiative and American College of Physicians (ACP) agree that synovial fluid analysis is the reference standard to evaluate the diagnostic performance of clinical algorithms, laboratory and imaging findings such as ultrasonography (US), conventional radiography, and dual-energy computed tomography (DECT) (Sivera F 2014, Qaseem A 2017a). The 3e Initiative stated by expert consensus that the detection of MSU crystals is required ( $\mathrm{Si}$ vera F 2014). The ACP Diagnosis 2017 pointed out that evidence for alternatives to synovial fluid MSU crystal analysis is limited (Qaseem A 2017a). Clinical algorithms as well as imaging should be further tested to be supported for routine clinical purposes (Qaseem A 2017a)

Benefits, harmful effects and barriers to implementation. Benefits: Accurate diagnosis of gout, leading to appropriate treatment. Harmful effects: Misdiagnosis or delayed diagnosis, leading to inadequate or inappropriate treatment. Synovial fluid aspiration for MSU analysis associated mostly with nonserious adverse events, such as mild post-procedure pain, and rarely with serious adverse events such as septic arthritis. None reported for DECT and US. Barriers: Synovial fluid analysis for identification of MSU crystals and the use of advanced imaging techniques (DECT and US) might prove difficult in some settings in routine clinical practice (availability, cost and the need for trained personnel and specific equipment).

\section{Recommendation 2:}

\section{Assessment of co-morbidities}

Summary of evidence linked to recommendation. Comorbidities associated with gout and the importance of screening and the need to manage these co-morbidities are well recognized from observational and population-based studies (Sing JA 2011, Primatesta P 2011, De Vera MA 2010, Teng GG 2012).

Benefits, harmful effects and barriers to implementation. Benefits: detection and treatment of early diseases which are known to be associated with gout, such as metabolic syndrome, cardiovascular diseases, and renal disease. Detection of unusual causes of gout (potential genetic or acquired cause of uric acid overproduction) and their proper treatment. Harmful effects: exposure of patients to an excess of examinations or tests; healthcare system costs. Barriers: extensive screening may be timeconsuming and difficult to be implemented in nondedicated settings.
Recommendation 3:

\section{Time to treatment of acute gout}

Summary of evidence linked to recommendation. This recommendation was mainly based on expert opinion, patient experience and patient-reported outcomes. Two RCTs demonstrated reduction of pain within $24 \mathrm{~h}$ following treatment with a NSAID (Garcia de la Torre I 1987) and with colchicine (Terkeltaub RA 2010). A proof of concept study supported the strategy of providing the patients with instructions to initiate treatment without the need to consult their health care practitioner (Ress F 2013).

Benefits, harmful effects and barriers to implementation. Benefits: early treatment in fully educated patients may reduce the need for long-standing treatments and access to health care facilities. Harmful effects: encouraging self-medication may discourage patient follow-up as part of a treat-to-target strategy. The risk of adverse events due to inadequate use of medications may be increased. Barriers: patients may not be inclined towards or suitable for a self-medication strategy due to lack of compliance.

\section{Recommendation 4:}

\section{First-line therapy in acute gout}

Summary of evidence linked to recommendation. Evidence from RCTs is insufficient to prioritize between these options (Wechalekar MD 2014). The efficacy of colchicine and NSAIDs was demonstrated in RCTs (Terkeltaub RA 2010, Ahern MJ 1987, Garcia de la Torre I 1987). Low-dose colchicine was as effective as high-dose colchicine but with a safety profile comparable to that of a placebo, while high doses were significantly more likely to be associated with adverse effects (Terkeltaub RA 2010). The prescription of NSAIDs at high dose in acute gout due to the severity of the pain and inflammation is based on widespread expert consensus (Khanna D 2012b, Hui M 2017). Equivalent efficacy of NSAIDs (naproxen and indomethacin) and prednisolone was shown in two RCTs (Janssens HJ 2008, Rainer TH 2016). Small observational studies and expert opinion suggest that intra-articular and intramuscular steroid injections can be effective treatments for acute gout (Fernandez C 1999, Alloway JA 1993, Siegel LB 1994). Therefore, the choice is at the discretion of the prescribing physicians based on the patient's characteristics and on the presence or absence of contraindications. Although in most patients who were prescribed NSAIDs at least one contraindication was found in comparison with the minority of patients who received colchicine (Keenan RT 2011), NSAIDs are used more often than colchicine in general practice (Roddy E 2007). As reported in a survey, the combination of agents like 
NSAIDs, colchicine, or intra-articular / oral corticosteroids is commonly used (Schlesinger N 2006). Benefits, harmful effects and barriers to implementation. Benefits: in addition to evidence of similar efficacy between drugs, the optimal choice of pharmacologic treatment for acute gout may improve safety issues. Harmful effects: colchicine may produce gastrointestinal side effects, most frequently diarrhea, and drug interactions with inhibitors of cytochrome P450 3A4 and of P-glycoprotein and severe renal impairment may highly increase the risk of adverse events. NSAIDs are associated with minor (dyspepsia) to serious gastrointestinal adverse effects (perforations, ulcers, and bleeding) more frequently than cyclooxygenase- 2 inhibitors and corticosteroids. Long-term use of high doses can cause chronic renal insufficiency whereas long-term use of corticosteroids is associated with adverse effects that are dose- and duration dependent and affect the body diffusely (dysphoria, mood disorders, elevation of blood glucose levels, immune suppression, and fluid retention). Combination therapies may increase the risk of adverse events, particularly in patients with multiple contraindications. Barriers: in Italy colchicine is available only in $1 \mathrm{mg}$ tablets. Intra-articular injection of corticosteroids may not be practical in many primary care settings.

\section{Recommendation 5:}

\section{Second-line and adjunctive}

therapies in acute gout

Summary of evidence linked to recommendation. A uniform definition of an inadequate response to the initial pharmacologic therapy for acute gout is lacking in literature and alternative diagnoses to gout should be always considered in non-responders. An RCT showed that the IL-1b antibody canakinumab (150 mg by subcutaneous injection) is efficacious compared with $40 \mathrm{mg}$ intramuscular triamcinolone acetonide (Schlesinger N 2011, Schlesinger N 2011). An RCT demonstrated that the receptor fusion protein antilL- $1 \alpha / 1 \beta$ rilonacept (320 $\mathrm{mg}$ by subcutaneous injection) provided no benefit over indomethacin (Terkeltaub RA 2013). An uncontrolled trial on anakinra (100 mg subcutaneously daily for 3 consecutive days) (So A 2007) and a retrospective review of its offlabel use suggested that it can be effective and safe in patients who fail or cannot undergo conventional therapy (Ghosh P 2013). A small RCT showed that topical ice was effective when added to prednisolone and colchicine (Moi JH 2014). No RCTs of rest were undertaken in patients with gout. Paracetamol as adjunct analgesic therapy is based on expert opinion ( $\mathrm{Si}$ vera F 2014). The effectiveness of traditional Chinese medicine, including herbs and acupuncture, is not supported by sufficient evidence (Qaseem A 2017b). Benefits, harmful effects and barriers to implementation. Benefits: optimal control of severe diseases. Harmful effects: the risk of sepsis in patients receiving IL-1 blockers is augmented. The use of anti-IL-1 biologics may underestimate the importance of lower SUA levels. Anti-IL1 biologics strategy is currently not cost-effective. Barriers: Prescribers should be aware of the potential need to obtain approval for an individual funding request before anti-IL1 are used. The use of anakinra is not licensed for gout and is frequently limited by reactions at the injection site. Rilonacept is not commercially available in Italy.

\section{Recommendation 6:}

\section{Timely treatment of hyperuricemia in gout}

Summary of evidence linked to recommendation. The importance of providing full information and involving the patient in the decision-making process is highlighted to ensure adherence to ULT as observed in studies and in a survey (Rees F 2013, Harrold LR 2012, Li QH 2013, Te Karu L 2013). The impact of ULT (allopurinol and febuxostat) on SUA levels has been demonstrated by high-quality evidence from 4 RCTs (Schumacher HR Jr 2008, Becker MA 2005, Becker MA 2010, Becker MA 2009). Then, the efficacy of treatment of patients with recurring attacks ( $\geq 2$ episodes per year), tophi and chronic gouty arthritis is supported by systematic reviews and meta-analyses (Faruque LI 2013, Sriranganathan MK 2014, Ye P 2013). Large trials based on observational evidence have shown consistently that appropriate ULT reduces the frequency of gout flare, the size and number of tophi and avoids their recurrence (though not within the first 6 months) (Schumacher HR Jr 2008, Becker MA 2005, Becker MA 2008, Wu EQ 2009, Khanna PP 2013, Hamburger MI 2012), thereby improving the quality of life (Strand V 2012, Richette P 2012). However, the recommendation to consider treatment with ULT in all patients with gout is only based on expert opinion. No studies focused on the benefits of long-term use ( $\geq 12$ months) after the first attack or in infrequent attacks $(<2$ episodes per year) in patients with single or infrequent gout attacks $(<2$ per year) (Qaseem A 2017b). Early treatment in patients with cardiovascular and renal comorbidities is supported by a cohort study of (Rothenbacher D 2011). The commencement of ULT is traditionally delayed after the attack ( 2 weeks' delay). However, neither the duration of flares nor their severity were worsened by immediate allopurinol initiation compared with delayed initiation in two small RCTs (Taylor TH 2012, Hill EM 2015). Moreover, it is widespread expert opinion that postponing discussion of long term ULT until the attack has resolved would allow information (including continuation of ULT during flare) to be better absorbed (Khanna D 2012b, Hui M 2017).

Benefits, harmful effects and barriers to implementation. Benefits: individuation of patients who need long-life ULT may prevent administration of ULT in patients who will not benefit. Early treatment may prevent the increase of uric acid burden in patients at gout onset and the evolution into severe disease. Patient education may improve adherence to ULT, which is a major issue in gout treatment failure. 
Harmful effects: indiscriminate ULT prescription to all patients may increase the rate of adverse events due to unnecessary drug exposure. Barriers: patient education may be time-consuming and of difficult implementation in non-dedicated settings.

\section{Recommendation 7: \\ First-line ULT in gout}

Summary of evidence linked to recommendation. Allopurinol is a purine analogue which acts as xanthine oxidase inhibitor (XOI). The efficacy and safety of allopurinol has been studied in several trials in comparison with placebo, febuxostat, benzbromarone, colchicine, and probenecid, and continuous $v s$. intermittent allopurinol at variable doses (Seth R 2014). In RCTs, allopurinol $300 \mathrm{mg}$ daily was more effective than placebo (Schumacher HR Jr 2008) but less effective than febuxostat $80 \mathrm{mg}$ or $120 \mathrm{mg}$ daily (Schumacher HR Jr 2008, Becker MA 2010). Allopurinol in doses of $300 \mathrm{mg}$ or less daily is often not associated with the achievement of target SUA levels in many patients (Rees F 2013, Becker MA 2010, Reinders MK 2009). The median dose found to be required for a SUA target of $6 \mathrm{mg} / \mathrm{dl}(360 \mu \mathrm{mol} / \mathrm{L})$ was $400 \mathrm{mg}$ daily with high success rate up to $800 \mathrm{mg}$ daily (Rees F 2013, Reinders MK 2009). Up-titration of allopurinol is effective in lowering SUA levels and generally well tolerated and if started at a low dose (100 mg daily) reduces early gout flare (Rees F 2013, Jennings CG 2014).

Benefits, harmful effects and barriers to implementation. Benefits: the use of allopurinol as first-line ULT is effective, inexpensive, easy to titrate and well tolerated by the majority of patients. Harmful effects: uptitration and inadequate dose increase may not be associated with the achievement of recommended SUA target levels. Moreover, high starting doses of allopurinol might increase the risk of serious adverse reactions including drug hypersensitivity syndrome with rash, eosinophilia and systemic symptoms (DRESS), toxic epidermal necrolysis, Stevens-Johnson syndrome, and major end-organ disease with liver and renal toxicity (Stamp LK 2012, Lupton G 1979, Arellano F 1993, Zineh I 2011, Kim SC 2013). Barriers: up-titration strategy may require a rigorous follow-up which could not be provided in non-dedicated settings.

\section{Recommendation 8: \\ Second-line and combination ULTs in gout}

Summary of evidence linked to recommendation. Febuxostat is a potent non-purine selective XOI and it is metabolized in the liver. Its renal excretion is not a major route of elimination, which allows for its use in patients with mild-to-moderate kidney failure (GFR $>30 \mathrm{ml} / \mathrm{min} / 1.73 \mathrm{~m}^{2}$ ). The efficacy of febuxostat in reducing SUA levels and the risk of gout flares has been demonstrated in systematic reviews and metaanalysis of RCTs (Faruque LI 2013, Ye P 2013). Compared to allopurinol $300 \mathrm{mg}$, febuxostat (80mg and $120 \mathrm{mg} /$ day) was more effective in reducing the SUA levels but not the risk of gout flares (Becker MA 2010, Becker MA 2005, Schumacher HR Jr 2008). Febuxostat is generally well tolerated: severe cutaneous hypersensitivity reactions are very unusual and data do not support any cross-reactivity with allopurinol but careful follow-up of these patients is needed (Abeles AM 2012, Chohan S 2011, Bardin T 2016). Treatment with febuxostat in patients with a history of ischemic heart disease or congestive heart failure is not recommended by the European Medicine Agency (EMA) and studies on its cardiovascular safety are in progress. Traditional uricosurics (sulfinpyrazone, probenecid, benzbromarone) are recognized as a valuable component of comprehensive ULT by a systematic review and meta-analysis of two RCTs (Kydd ASR 2014). However, the use of benzbromarone was restricted in Europe following rare reports of severe hepatotoxicity. The only uricosuric available for use in gout in Italy is lesinurad (European Medicine Agency), whereas probenecid and benzbromarone are not commercially available and sulfinpyrazone is not approved for this use. All traditional uricosurics need to be used with caution in patients with urolithiasis and have limited efficacy in mild-to-moderate renal impairment (benzbromarone to a lesser extent than sulfinpyrazone and probenecid (Perez-Ruiz F 1999), whereas they are contraindicated in severe renal failure. The recommendation for combination therapy with XOI plus a uricosuric is based on limited trials on allopurinol-probenecid, -benzbromarone or -sulfinpyrazone vs. allopurinol alone (Pui K 2013, Reinders MK 2007, Stocker SL 2011, Perez-Ruiz F 2002, Azevedo F 2014). RCTs have shown that lesinurad is effective in combination with allopurinol (Saag KG 2014) and new evidence is awaited. A case report suggested that allopurinol combined with febuxostat and benzbromarone could be effective in lowering the SUA (Maekawa M 2014). However, important drug label information states, among other things, that the combination of febuxostat with other xanthine oxidase substrate drugs, such as allopurinol, should be avoided (Khanna D 2012a) unless necessary since drug interaction studies have been performed (European Medicine Agency). In case of refractoriness to, or intolerance of, conventional and appropriately dosed ULT, a uricase (pegloticase and rasburicase) could be considered (Sriranganathan MK 2014). Pegloticase administered by i.v. infusion ( $8 \mathrm{mg}$ in $250 \mathrm{ml}$ normal saline over $2 \mathrm{~h}$ ) every 2 weeks with pre-treatment with antihistamines and steroids to reduce the risk of infusion reactions in addition to low dose colchicine or NSAIDs for flare prophylaxis, is effective (Sundy JS 2011, Baraf HS 2013, Lipsky PE 2014). Pegloticase is contraindicated in patients with glucose-6-phosphate dehydrogenase deficiency (risk of hemolysis) and caution is required for concurrent congestive heart failure (Hui M 2017). There is no consensus about the duration of treatment with pegloticase and a switch may be considered, if feasi- 
ble, toward an oral ULT once tophi have disappeared (Hui M 2017). Despite the favorable opinion of the EMA on the benefit-risk balance of the medicinal product containing pegloticase, in July 2016 marketing authorization for pegloticase was withdrawn for use in European Union due to commercial reasons (European Medicine Agency). Rasburicase was used successfully in some patients with severe refractory gout, but showed a great potential immunogenicity (Richette P 2007).

The mild uricosuric effects of anti-hypertensive losar$\tan$ (Wurzner G 2011, Choi HK 2012) and lipid-lowering agent fenofibrate (Desager JP 1980) were documented and their additional urate-lowering efficacy when administered to gout patients receiving ULT with allopurinol or benzbromarone could be considered (Takahashi S 2003). In addition to losartan, calcium blockers should be considered (Abdellatif AA 2014), and the uricosuric property of statins has been further documented (Ogata N 2010, Takagi H 2012). An RCT meta-analysis showed that vitamin C supplementation (particularly $>500 \mathrm{mg} /$ day) can lower SUA levels (Juraschek SP 2011), but the weak uricosuric effect is insufficient for it to be used as substitute monotherapy (Stamp LK 2013).

Benefits, harmful effects and barriers to implementation. Benefits: the use of a stepwise approach may reduce the risk of adverse events and be cost-effective. The adjunctive therapy may optimize the management of gout and the use of other ULTs in a comprehensive strategy. Harmful effects: the achievement of SUA target levels may be slowed and patients may be exposed to high uric acid overload. Uricases have great potential immunogenicity with high risk of infusion reactions and anaphylaxis. Barriers: Uricosurics are not available in Italy with the exception of lesinurad which has only recently been licensed for commercialization and use in gout. Pegloticase was withdrawn for use in the European Union. Rasburicase is not licensed for the treatment of gout and prescribers should be aware that approval is needed for its off-label use as well as for an individual funding request before use. Due to these limitations, the route of administration (intravenous) and potential immugenicity of rasburicase and pegloticase, patients should to be referred to secondary or tertiary centers.

\section{Recommendation 9: \\ Flare prophylaxis}

Summary of evidence linked to recommendation. When ULT is started, the rate of gout attacks is recognized as increasing due to dispersion of MSU crystals during the initial phase of deposit dissolution (Wortmann RL 2010). High-quality evidence supports prophylaxis (low-dose colchicine or low-dose NSAIDs) against acute flares in patients initiating ULT (Seth R 2014, Latourte A 2014). However, low initial doses and slow up-titration of ULT can be also considered as part of flare prevention (Rees F 2013). When febuxostat is started, flare prophylaxis is particularly important, as the risk of gout flare is greater due to its having a greater SUA lowering effect than the starting dose of allopurinol (100 mg) (Faruque LI 2013). There is evidence from RCTs to support the use of colchicine, rather than NSAIDs, for flare prophylaxis (Paulus HE 1974, Borstad GC 2004, Wortmann RL 2010, Terkeltaub RA 2011). As an alternative treatment, low-dose prednisone (or prednisolone) could be considered, but the use of corticosteroids for flare prophylaxis is not supported by evidence (Hui M 2017). IL-1 inhibitors have also been investigated for use for flare prophylaxis but none are currently approved for this indication (Schlesinger N 2011, Karimzadeh H 2006, Mitha E 2013, Schumacher HR Jr 2013, Sundy JS 2013).

The optimal duration of prophylaxis is currently unclear (Seth R 2014, Karimzadeh H 2006). Continuing prophylactic treatment for more than 8 weeks was more effective than shorter durations and acute gout flares did not increase in trials with prophylaxis up to 6 months (Schumacher HR Jr 2008, Becker MA 2005, Becker MA 2010, Wortmann LR 2010). Evidence is insufficient to support further continuation of pharmacologic prophylaxis and the recommendations are based on expert opinions (Khanna D 2012b).

Benefits, harmful effects and barriers to implementation. Benefits: Appropriate prophylaxis may improve adherence to ULTs which is known to be low. Harmful effects: Long-term prophylaxis may expose patients to adverse events without an impact on gouty arthritis management. Barriers: None.

\section{Recommendation 10:}

\section{Lifestyle interventions}

Summary of evidence linked to recommendation. There is growing evidence regarding the importance of education in gout together with general lifestyle advice (Rees F 2013). Current understanding is largely derived from epidemiological studies. Consumption of meat, seafood, alcoholic beverages (particularly beer and spirits), sugar-sweetened soft drinks and fructose-containing foods are all significant risk factors for incident gout or recurrent gout attacks (Choi HK 2004, Choi HK 2004, Choi HK 2010, Choi HK 2008, Singh JA 2011, Zhang Y 2012, Neogi T 2014). Sparse data on the protective role against incident gout and recurrent flares are available for lowfat dairy intake, skimmed milk powder enriched with glycomacropeptides, folate intake, coffee consumption, diets high in fiber, fruit consumption (particularly if vitamin-C rich and particularly cherries) (Dalbeth N 2012, Zhang Y 2012). However, a general lack of specific evidence from trials yielded an approach based on the diet and lifestyle measures which were recommended for the promotion and the maintenance of ideal health and the prevention of co-morbidities, including coronary artery disease, obesity, metabolic syndrome, diabetes mellitus, hyperlipidemia and hypertension. Finally, diet and lifestyle measures alone are recognized as not providing sufficient SUA-low- 
ering effects and/or gout attack prophylaxis in many patients with gout (Choi HK 2010, Singh JA 2011). Benefits, harmful effects and barriers to implementation. Benefits: optimization of gout management further to pharmacologic treatment and add-on strategies. Harmful effects: emphasis on diet and lifestyle interventions may unduly overshadow the pharmacologic treatment which is the mainstay in gout management. Barriers: healthcare professionals need to receive a specialized training. Patient education is time-consuming and may be difficult in non-dedicated settings.

\section{Recommendation 11:}

\section{Management points in special groups}

Summary of evidence linked to recommendation. Chronic kidney disease (CKD) and nephrolithiasis are very common in patients with gout and the management of gout in these patients may be challenging (Roughly MJ 2015). The dose of oral colchicine should be reduced in patients with mild-to-moderate renal impairment (eGFR $10-50 \mathrm{ml} / \mathrm{min} / 1.73 \mathrm{~m}^{2}$ ) and it is contraindicated in more severe renal disease (eGFR $<10 \mathrm{ml} / \mathrm{min} / 1.73 \mathrm{~m}^{2}$ ) due to increased toxicity (especially myopathy) (Wallace SL 1991). Similarly, high-dose NSAIDs should be avoided in moderateto-severe renal impairment due to the possibility of acute kidney injury (Ungprasert P 2015) whereas no evidence of accelerated CKD progression was found in patients with moderate-to-severe renal impairment treated with low-dose NSAIDs (Nderitu P 2013). Prophylaxis with low-dose colchicine, adjusted for renal function, is believed to be a safer option than lowdose NSAIDs (Curiel RV 2012, Abdellatif AA 2014). In those with CKD the use of corticosteroids (oral course or intra-articular injection) is based on clinical experience and expert consensus (Hui M 2017). The greatest concern with the use of allopurinol in patients with renal failure is the development of severe adverse reaction, including DRESS, Stevens-Johnson syndrome and toxic epidermal necrosis, which allopurinol was found to be the drug most associated with in Europe (Halevy S 2008). However, lowering the starting dose of allopurinol in relation to the level of renal function seems to reduce the risk of allopurinol hypersensitivity without any increase in toxicity (Stamp LK 2011) but findings are not consistent (Vazquez-Mellado J 2001) and dose adjustment according to renal function seldom resulted in adequate reduction of SUA levels (Dalbeth N 2006). In patients with $\mathrm{CKD}$, febuxostat was found to be more effective than allopurinol (Becker MA 2010, Reinders MK). Benzbromarone, which is predominately metabolized by the liver, is an option but not recommended in patients with eGFR $<30 \mathrm{~mL} / \mathrm{min} / 1.73 \mathrm{~m}^{2}$ (Perez-Ruiz F 1999, Fujimori S 2011).

Moreover, subjects carrying the HLA-B*5801 allele and of Korean descent with stage 3 CKD or worse, or of Han Chinese or Thai extraction irrespective of renal function, remain at high risk for allopurinol hypersen- sitivity (Jung JW 2011, Hung SI 2005, Tassaneeyakul W 2009, Hershfield MS 2013, Zineh I 2011). In such high-risk individuals, HLA- B*5801 testing should be considered prior to the initiation of allopurinol and an alternative ULT should be prescribed to patients known to carry the HLA-B*5801 allele. To manage gouty attack in NPO patients, which are common in the inhospital setting due to different surgical and medical conditions, sporadic studies offer appropriate options such as intra-articular injection of corticosteroids (Fernandez C 1999), intravenous or intramuscular methylprednisolone (Groff GD 1990), and subcutaneous synthetic Corticotropin (ACTH) (Janssens HJ 2008). Benefits, harmful effects and barriers to implementation. Benefits: reduction and prevention of major adverse events related to pharmacologic therapy of gout in patients with renal impairment or special populations. Harmful effects: undertreatment of gout in these patients. Barriers: performing the HLA-B*5801 test may be restricted to tertiary centers and screening all patients with gout is not cost-effective.

\section{Recommendation 12: Co-prescriptions}

Summary of evidence linked to recommendation. This recommendation explicitly underlines the need to pay attention to co-prescriptions of colchicine with P-glycoprotein and/or CYP3A4 inhibitors and statins (Khanna D 2012b, Richette P 2017). Major colchicine drug interactions include those with clarithromycin, erythromycin, cyclosporine, disulfiram, verapamil, and ketoconazole (Terkeltaub RA 2011, Keenan RT 2011). The co-prescription of colchicine and statins requires caution, especially in patients with renal impairment, as cases of myopathy and rhabdomyolysis following combined use were reported. (Hsu WC 2002, Justiniano M 2007, Tufan A 2006). Diuretics have been found to be associated with an increased risk of gout (Report Lancet 1981), particularly thiazide and loop diuretics but not potassium-sparing diuretics (Hueskes BAA 2012). However, evidence is insufficient to recommend the discontinuation of diuretics across all the indications in patients with gout (Bruderer S 2014).

Benefits, harmful effects and barriers to implementation. Benefits: prevention of adverse events related to drug administration in gout. Harmful effects: none. Barriers: none.

\section{Recommendation 13: Management of tophi}

Summary of evidence linked to recommendation. In patients with severe symptomatic tophaceous gout, referral to a specialist should be considered (Khanna D 2012a, Hui M 2017). Evidence for the use of surgery to treat tophi came only from case reports and case series (Sivera F 2014).

Benefits, harmful effects and barriers to implementation. Benefits: improved treatment of severe gout and tophi. Harmful effects: Surgery for tophi may not be resolutive and patients may need to be retreated. Barriers: Surgery may not be promptly available in nondedicated settings. 


\section{Recommendation 14: Therapeutic targets}

Summary of evidence linked to recommendation. A treat-to-target strategy is recommended for every patient with gout (Klitz U 2017). Several tools have been used for monitoring the different outcome domains in patients with gout, including biological markers, clinical features, patient-reported outcomes, and imaging (Becker MA 2009, Khanna PP 2011, AlvarezHernandez E 2008, Dalbeth N 2007, Perez-Ruiz F 2007). The levels of SUA are used as a surrogate marker to monitor gout (Sivera F 2014). Levels $<6$ $\mathrm{mg} / \mathrm{dl}$ are below the saturation point for MSU (Bardin T 2015), normal SUA levels dissolve crystal deposits (Pascual E 2007) and the velocity of crystal dissolution depends on the SUA level (Perez-Ruiz F 2007, Perez-Ruiz F 2002, Perez-Ruiz F 2011). Moreover, the SUA level is particularly useful for monitoring adherence, since poor adherence to ULT is a major issue in gout patients (Harrold LR 2009). Besides, some studies have suggested that SUA might be protective against several neurodegenerative diseases and an association between low SUA levels $(<3 \mathrm{mg} / \mathrm{dl})$ and some neurodegenerative diseases was observed (Chen H 2009, Weisskopf MG 2007, Kim TS 2006, Abraham A 2014, Ascherio A 2009, Euser SM 2009, Auinger P 2010, Paganoni S 2012, Jain S 2011). Finally, evidence is insufficient to determine the criteria for discontinuing ULT (Loebl WY 1974, Perez-Ruiz F 2011) and high recurrence of flare 5 years after withdrawal of ULT was observed (Perez-Ruiz F 2011).

Benefits, harmful effects and barriers to implementation. Benefits: monitoring gouty patients may help improve adherence to treatment and overall management of gout. Harmful effects: low SUA levels $(<3$ $\mathrm{mg} / \mathrm{dl}$ ) could be associated with neurodegenerative diseases. Barriers: further to SUA levels, the role of other outcomes such as clinimetrics, imaging and biomarkers is still to be clearly defined.

\section{REFERENCES (ALPHABETICAL ORDER)}

Abdellatif AA, Elkhalili N. Management of gouty arthritis in patients with chronic kidney disease. Am J Ther. 2014; 21: 523-34.

Abeles AM. Febuxostat hypersensitivity. J Rheumatol. 2012; 39: 659 .

Abraham A, Drory VE. Influence of serum uric acid levels on prognosis and survival in amyotrophic lateral sclerosis: a meta-analysis. J Neurol. 2014; 261: 1133-8.

Ahern MJ, Reid C, Gordon TP, McCredie M, Brooks PM, Jones M. Does colchicine work? The results of the first controlled study in acute gout. Aust N Z J Med. 1987; 17: 301-4.

Alloway JA, Moriarty MJ, Hoogland YT, Nashel DJ. Comparison of triamcinolone acetonide with indomethacin in the treatment of acute gouty arthritis. J Rheumatol. 1993; 20: 111-3.

Alvarez-Hernández E, Peláez-Ballestas I, Vázquez-Mellado J, Terán-Estrada L, Bernard-Medina AG, Espinoza J, et al. Validation of the Health Assessment Questionnaire disability index in patients with gout. Arthritis Rheum. 2008; 59: 665-9.

Arellano F, Sacristán JA. Allopurinol hypersensitivity syndrome: a review. Ann Pharmacother. 1993; 27: 337-43.

Ascherio A, LeWitt PA, Xu K, Eberly S, Watts A, Matson WR, et al. Urate as a predictor of the rate of clinical decline in Parkinson disease. Arch Neurol. 2009; 66: 1460-8.

Auinger P, Kieburtz K, McDermott MP. The relationship between uric acid levels and Huntington's disease progression. Mov Disord. 2010; 25: 224-8.

Azevedo VF, Buiar PG, Giovanella LH, Severo CR, Carvalho M. Allopurinol, benzbromarone, or a combination in treating patients with gout: analysis of a series of outpatients. Int J Rheumatol. 2014; 2014: 263720.

Baraf HS, Becker MA, Gutierrez-Urena SR, Treadwell EL, Vazquez-Mellado J, Rehrig CD, et al. Tophus burden reduction with pegloticase: results from phase 3 randomized trials and open-label extension in patients with chronic gout refractory to conventional therapy. Arthritis Res Ther. 2013; 15: R137.

Bardin T. Hyperuricemia starts at 360 micromoles $(6 \mathrm{mg} / \mathrm{dl})$. Joint Bone Spine. 2015; 82: 141-3.

Bardin T, Chalès G, Pascart T, Flipo RM, Korng Ea H, Roujeau JC, et al. Risk of cutaneous adverse events with febuxostat treatment in patients with skin reaction to allopurinol. A retrospective, hospital-based study of 101 patients with consecutive allopurinol and febuxostat treatment. Joint Bone Spine. 2016; 83: 314-7.

Beard SM, von Scheele BG, Nuki G, Pearson IV. Cost-effectiveness of febuxostat in chronic gout. Eur J Health Econ. 2014; 15: 453-63.

Becker MA, Schumacher HR Jr, Wortmann RL, MacDonald PA, Palo WA, Eustace D, et al. Febuxostat, a novel nonpurine selective inhibitor of xanthine oxidase: a twenty-eight-day, multicenter, phase II, randomized, double-blind, placebo-controlled, dose-response clinical trial examining safety and efficacy in patients with gout. Arthritis Rheum. 2005; 52: 916-23.

Becker MA, MacDonald PA, Hunt BJ, Lademacher C, Joseph-Ridge N. Determinants of the clinical outcomes of gout during the first year of urate-lowering therapy. Nucleosides Nucleotides Nucleic Acids. 2008; 27: 585-91.

Becker MA, Schumacher HR, Benjamin KL, Gorevic P, Greenwald M, Fessel J, et al. Quality of life and disability in patients with treatment-failure gout. J Rheumatol. 2009; 36: 1041-8.

Becker MA, Schumacher HR, MacDonald PA, Lloyd E, Lademacher C.J Rheumatol. Clinical efficacy and safety of successful longterm urate lowering with febuxostat or allopurinol in subjects with gout. 2009; 36: 1273-82.

Becker MA, Schumacher HR, Espinoza LR, Wells AF, MacDonald P, Lloyd E, et al. The urate-lowering efficacy and safety of febuxostat in the treatment of the hyperuricemia of gout: the CONFIRMS trial. Arthritis Res Ther. 2010; 12: R63.

Borstad GC, Bryant LR, Abel MP, Scroggie DA, Harris MD, Alloway JA. J Rheumatol. Colchicine for prophylaxis of acute flares when initiating allopurinol for chronic gouty arthritis. 2004; 31: 2429-32. 
Bruderer S, Bodmer M, Jick SS, Meier CR. Use of diuretics and risk of incident gout: a population-based case-control study. Arthritis Rheumatol. 2014; 66: 185-96.

Chen H, Mosley TH, Alonso A, Huang X. Plasma urate and Parkinson's disease in the Atherosclerosis Risk in Communities (ARIC) study. Am J Epidemiol. 2009; 169: 1064-9.

Chohan S. Safety and efficacy of febuxostat treatment in subjects with gout and severe allopurinol adverse reactions. J Rheumatol. 2011; 38: 1957-9.

Choi HK, Atkinson K, Karlson EW, Willett W, Curhan G. Purine-rich foods, dairy and protein intake, and the risk of gout in men. N Engl J Med. 2004; 350: 1093-103.

Choi HK, Atkinson K, Karlson EW, Willett W, Curhan G. Alcohol intake and risk of incident gout in men: a prospective study. Lancet. 2004; 363: 1277-81.

Choi HK, Curhan G.BMJ. Soft drinks, fructose consumption, and the risk of gout in men: prospective cohort study. 2008; 336: 309-12.

Choi HK, Willett W, Curhan G. Fructose-rich beverages and risk of gout in women. JAMA. 2010; 304: 2270-8.

Choi HK. A prescription for lifestyle change in patients with hyperuricemia and gout. Curr Opin Rheumatol. 2010; 22: 165-72.

Choi HK, Soriano LC, Zhang Y, Rodríguez LA. Antihypertensive drugs and risk of incident gout among patients with hypertension: population based case-control study. BMJ. 2012; 344: d8190.

Curiel RV, Guzman NJ. Challenges associated with the management of gouty arthritis in patients with chronic kidney disease: a systematic review. Semin Arthritis Rheum. 2012; 42: 166-78.

Dalbeth N, Kumar S, Stamp L, Gow P. Dose adjustment of allopurinol according to creatinine clearance does not provide adequate control of hyperuricemia in patients with gout. J Rheumatol. 2006; 33: 1646-50.

Dalbeth N, Clark B, Gregory K, Gamble GD, Doyle A, McQueen FM. Computed tomography measurement of tophus volume: comparison with physical measurement. Arthritis Rheum. 2007; 57: 461-5.

Dalbeth N, Ames R, Gamble GD, Horne A, Wong S, KuhnSherlock B, et al. Effects of skim milk powder enriched with glycomacropeptide and G600 milk fat extract on frequency of gout flares: a proof-of-concept randomised controlled trial. Ann Rheum Dis. 2012; 71: 929-34.

De Vera MA, Rahman MM, Bhole V, Kopec JA, Choi HK. Independent impact of gout on the risk of acute myocardial infarction among elderly women: a population-based study. Ann Rheum Dis. 2010; 69: 1162-4.

Desager JP, Hulhoven R, Harvengt C. Uricosuric effect of fenofibrate in healthy volunteers. J Clin Pharmacol. 1980; 20(10): 560-4.

European Medicine Agency. Adenuric - EMEA/H/C/000777 -PSUSA/00001353/201704. European public assessment report - Product Information. Last updated March 27th, 2018. http://www.ema.europa.eu/docs/en_GB/document library/EPAR_-_Product_Information/human/000777/ WC500021812.pdf (accessed April 25th, 2018).

European Medicine Agency. Krystexxa - EMA/498114/2016. Withdrawal of the marketing authorisation in the European
Union. July 21st, 2016. http://www.ema.europa.eu/docs/ en_GB/document_library/Public_statement/2016/07/ WC500210911.pdf (accessed April 25th, 2018).

European Medicine Agency. Krystexxa -EMEA/ H/C/002208 -PSUSA/00010046/201501. European public assessment report - Product Information. Last updated July 22nd, 2016. http://www.ema.europa.eu/docs/ en_GB/document_library/EPAR_-_Product_Information/human/002208/WC500138318.pdf (accessed April 25th, 2018).

European Medicine Agency. Zurampic - EMEA/H/C/003932 -IA/0008. European public assessment report - Product Information. Last updated July 6th, 2017. http://www. ema.europa.eu/docs/en_GB/document_library/EPAR_Product_Information/human/003932/WC500203066.pdf (accessed April 25th, 2018).

Euser SM, Hofman A, Westendorp RG, Breteler MM. Brain. Serum uric acid and cognitive function and dementia. 2009; 132: 377-82.

Faruque LI, Ehteshami-Afshar A, Wiebe N, Tjosvold L, Homik J, Tonelli M. A systematic review and metaanalysis on the safety and efficacy of febuxostat versus allopurinol in chronic gout.

Fernández C, Noguera R, González JA, Pascual E. Treatment of acute attacks of gout with a small dose of intraarticular triamcinolone acetonide. J Rheumatol. 1999; 26: 2285-6.

Fernández C, Noguera R, González JA, Pascual E. Treatment of acute attacks of gout with a small dose of intraarticular triamcinolone acetonide. J Rheumatol. 1999; 26: 2285-6.

Fujimori S, Ooyama K, Ooyama H, Moromizato H. Efficacy of benzbromarone in hyperuricemic patients associated with chronic kidney disease. Nucleosides Nucleotides Nucleic Acids. 2011; 30: 1035-8.

Garcia de la Torre I. A comparative double-blind parallel study with tenoxicam vs placebo in acute gouty arthritis. Invest Med Int. 1987; 14: 92-7.

Ghosh P, Cho M, Rawat G, Simkin PA, Gardner GC. Treatment of acute gouty arthritis in complex hospitalized patients with anakinra. Arthritis Care Res (Hoboken). 2013; 65: 1381-4

Groff GD, Franck WA, Raddatz DA. Systemic steroid therapy for acute gout: a clinical trial and review of the literature. Semin Arthritis Rheum. 1990; 19: 329-36.

Halevy S, Ghislain PD, Mockenhaupt M, Fagot JP, Bouwes Bavinck JN, Sidoroff A, et al. Allopurinol is the most common cause of Stevens-Johnson syndrome and toxic epidermal necrolysis in Europe and Israel. J Am Acad Dermatol. 2008; 58: 25-32.

Hamburger MI, Tesser JRP, Skosey JL, Morton AH, Kilgore KM. Arthritis Rheum. Patterns of gout treatment and related outcomes in US community rheumatology practices: the relation between gout flares, time in treatment, serum uric acid level, and urate lowering therapy. 2012; 64(Suppl 10): S808-9.

Harrold LR, Andrade SE, Briesacher BA, Raebel MA, Fouayzi H, Yood RA, et al. Adherence with urate-lowering therapies for the treatment of gout. Arthritis Res Ther. 2009; 11: R46. 
Harrold LR, Mazor KM, Peterson D, Naz N, Firneno C, Yood RA. Patients' knowledge and beliefs concerning gout and its treatment: a population based study. BMC Musculoskelet Disord. 2012; 13: 180.

Hershfield MS, Callaghan JT, Tassaneeyakul W, Mushiroda T, Thorn CF, Klein TE, et al. Clin Pharmacol Ther. Clinical Pharmacogenetics Implementation Consortium guidelines for human leukocyte antigen-B genotype and allopurinol dosing. 2013; 93: 153-8.

Hill EM, Sky K, Sit M, Collamer A, Higgs J. Does starting allopurinol prolong acute treated gout? A randomized clinical trial. J Clin Rheumatol. 2015; 21:120-5.

Hsu WC, Chen WH, Chang MT, Chiu HC. Colchicine-induced acute myopathy in a patient with concomitant use of simvastatin. Clin Neuropharmacol. 2002; 25: 266-8.

Hueskes BA, Roovers EA, Mantel-Teeuwisse AK, Janssens $\mathrm{HJ}$, van de Lisdonk EH, Janssen M. Use of diuretics and the risk of gouty arthritis: a systematic review. Semin Arthritis Rheum. 2012; 41: 879-89.

Hui M, Carr A, Cameron S, Davenport G, Doherty M, Forrester $\mathrm{H}$, et al. The British Society for Rheumatology Guideline for the Management of Gout. Rheumatology (Oxford). 2017; 56: 1056-1059.

Hung SI, Chung WH, Liou LB, Chu CC, Lin M, Huang HP, et al. HLA-B*5801 allele as a genetic marker for severe cutaneous adverse reactions caused by allopurinol. Proc Natl Acad Sci U S A. 2005; 102: 4134-9.

Jain S, Ton TG, Boudreau RM, Yang M, Thacker EL, Studenski S, et al. The risk of Parkinson disease associated with urate in a community-based cohort of older adults. Neuroepidemiology. 2011; 36: 223-9.

Janssens HJ, Janssen M, van de Lisdonk EH, van Riel PL, van Weel C.Lancet. Use of oral prednisolone or naproxen for the treatment of gout arthritis: a double-blind, randomised equivalence trial. 2008; 371: 1854-60.

Janssens HJ, Lucassen PL, Van de Laar FA, Janssen M, Van de Lisdonk EH. Systemic corticosteroids for acute gout. Cochrane Database Syst Rev. 2008; (2):CD005521.

Jennings CG, Mackenzie IS, Flynn R, Ford I, Nuki G, De Caterina $\mathrm{R}$, et al. Up-titration of allopurinol in patients with gout. Semin Arthritis Rheum. 2014; 44: 25-30.

Jung JW, Song WJ, Kim YS, Joo KW, Lee KW, Kim SH, et al. HLA-B58 can help the clinical decision on starting allopurinol in patients with chronic renal insufficiency. Nephrol Dial Transplant. 2011; 26: 3567-72.

Juraschek SP, Miller ER 3rd, Gelber AC. Arthritis Care Res (Hoboken). Effect of oral vitamin $\mathrm{C}$ supplementation on serum uric acid: a meta-analysis of randomized controlled trials. 2011; 63: 1295-306.

Justiniano M, Dold S, Espinoza LR. Rapid onset of muscle weakness (rhabdomyolysis) associated with the combined use of simvastatin and colchicine. J Clin Rheumatol. 2007; 13: 266-8.

Jutkowitz E, Choi HK, Pizzi LT, Kuntz KM. Cost-effectiveness of allopurinol and febuxostat for the management of gout. Ann Intern Med. 2014; 161: 617-26.

Karimzadeh H, Nazari J, Mottaghi P, Kabiri P. Different duration of colchicine for preventing recurrence of gouty arthritis. J Res Med Sci 2006; 11: 104-7.

Keenan RT, O'Brien WR, Lee KH, Crittenden DB, Fisher
MC, Goldfarb DS, et al. Prevalence of contraindications and prescription of pharmacologic therapies for gout. Am J Med. 2011; 124: 155-63.

Keenan RT, O'Brien WR, Lee KH, Crittenden DB, Fisher MC, Goldfarb DS, et al. Prevalence of contraindications and prescription of pharmacologic therapies for gout. Am J Med. 2011; 124: 155-63.

Khanna D, Fitzgerald JD, Khanna PP, Bae S, Singh MK, Neogi T, et al. 2012 American College of Rheumatology guidelines for management of gout. Part 1: systematic nonpharmacologic and pharmacologic therapeutic approaches to hyperuricemia. Arthritis Care Res (Hoboken). 2012; 64: 1431-46.

Khanna D, Khanna PP, Fitzgerald JD, Singh MK, Bae S, Neogi T, et al. Arthritis Care Res (Hoboken). 2012 American College of Rheumatology guidelines for management of gout. Part 2: therapy and antiinflammatory prophylaxis of acute gouty arthritis. 2012; 64: 1447-61.

Khanna PP, Perez-Ruiz F, Maranian P, Khanna D. Longterm therapy for chronic gout results in clinically important improvements in the health-related quality of life: short form-36 is responsive to change in chronic gout. Rheumatology (Oxford). 2011; 50: 740-5.

Khanna P, Khanna D, Storgard C, Baumgartner S, Morlock R. A world of hurt: failure to achieve treatment goals in patients with gout requires a paradigm shift. Postgrad Med. 2016; 128: 34-40.

Kiltz U, Smolen J, Bardin T, Cohen Solal A, Dalbeth N, Doherty M, et al. Treat-to-target (T2T) recommendations for gout. Ann Rheum Dis. 2017; 76: 632-638.

Kim SC, Schmidt BM, Franklin JM, Liu J, Solomon DH, Schneeweiss S. Clinical and health care use characteristics of patients newly starting allopurinol, febuxostat, and colchicine for the treatment of gout. Arthritis Care Res (Hoboken). 2013; 65: 2008-14.

Kim TS, Pae CU, Yoon SJ, Jang WY, Lee NJ, Kim JJ, et al. Decreased plasma antioxidants in patients with Alzheimer's disease. Int J Geriatr Psychiatry. 2006; 21: 344-8.

Kydd AS, Seth R, Buchbinder R, Edwards CJ, Bombardier C. Uricosuric medications for chronic gout. Cochrane Database Syst Rev. 2014; (11): CD010457.

Latourte A, Bardin T, Richette P. Prophylaxis for acute gout flares after initiation of urate-lowering therapy. Rheumatology (Oxford). 2014; 53: 1920-6.

Li QH, Dai L, Li ZX, Liu HJ, Zou CJ, Ou-Yang X, et al. Questionnaire survey evaluating disease-related knowledge for 149 primary gout patients and 184 doctors in South China. Clin Rheumatol. 2013; 32: 1633-40.

Lipsky PE, Calabrese LH, Kavanaugh A, Sundy JS, Wright D, Wolfson M, et al. Pegloticase immunogenicity: the relationship between efficacy and antibody development in patients treated for refractory chronic gout. Arthritis Res Ther. 2014; 16: R60.

Loebl WY, Scott JT. Withdrawal of allopurinol in patients with gout. Ann Rheum Dis. 1974; 33: 304-7. 14. Khanna D, Fitzgerald JD, Khanna PP, Bae S, Singh MK, Neogi T, et al. 2012 American College of Rheumatology guidelines for management of gout. Part 1: systematic nonpharmacologic and pharmacologic therapeutic ap- 
proaches to hyperuricemia. Arthritis Care Res (Hoboken). 2012; 64: 1431-46.

Lupton GP, Odom RB. The allopurinol hypersensitivity syndrome. J Am Acad Dermatol. 1979; 1: 365-74.

Maekawa M, Tomida H, Aoki T, Hishida M, Morinaga T, Tamai H. Successful treatment of refractory gout using combined therapy consisting of febuxostat and allopurinol in a patient with chronic renal failure. Intern Med. 2014; 53: 609-12.

Meltzer M1, Pizzi LT, Jutkowitz E. Payer decision-making with limited comparative and cost effectiveness data: the case of new pharmacological treatments for gout. Evid Based Med. 2012; 17: 105-8.

Mitha E, Schumacher HR, Fouche L, Luo SF, Weinstein SP, Yancopoulos GD, et al. Rilonacept for gout flare prevention during initiation of uric acid-lowering therapy: results from the PRESURGE-2 international, phase 3, randomized, placebo-controlled trial. Rheumatology (Oxford). 2013; 52: 1285-92.

Moi JH, Sriranganathan MK, Falzon L, Edwards CJ, van der Heijde DM, Buchbinder R. Lifestyle interventions for the treatment of gout: a summary of 2 Cochrane systematic reviews. J Rheumatol 2014; 92(Suppl): 26-32.

Nderitu P, Doos L, Jones PW, Davies SJ, Kadam UT. Nonsteroidal anti-inflammatory drugs and chronic kidney disease progression: a systematic review. Fam Pract. 2013; 30: 247-55.

Neogi T, Chen C, Niu J, Chaisson C, Hunter DJ, Zhang Y. Alcohol quantity and type on risk of recurrent gout attacks: an internet-based case-crossover study. Am J Med. 2014; 127: 311-8.

Ogata N, Fujimori S, Oka Y, Kaneko K. Effects of three strong statins (atorvastatin, pitavastatin, and rosuvastatin) on serum uric acid levels in dyslipidemic patients. Nucleosides Nucleotides Nucleic Acids. 2010; 29: 321-4.

Paganoni S, Zhang M, Quiroz Zárate A, Jaffa M, Yu H, Cudkowicz ME, et al. Uric acid levels predict survival in men with amyotrophic lateral sclerosis. J Neurol. 2012; 259: 1923-8.

Pascual E, Sivera F. Time required for disappearance of urate crystals from synovial fluid after successful hypouricaemic treatment relates to the duration of gout. Ann Rheum Dis. 2007; 66: 1056-8.

Paulus HE, Schlosstein LH, Godfrey RG, Klinenberg JR, Bluestone R. Prophylactic colchicine therapy of intercritical gout. A placebo-controlled study of probenecidtreated patients. Arthritis Rheum. 1974; 17: 609-14.

Perez-Ruiz F, Calabozo M, Fernandez-Lopez MJ, HerreroBeites A, Ruiz-Lucea E, Garcia-Erauskin G, et al. Treatment of chronic gout in patients with renal function impairment: an open, randomized, actively controlled study. J Clin Rheumatol. 1999; 5: 49-55.

Perez-Ruiz F, Calabozo M, Pijoan JI, Herrero-Beites AM, Ruibal A. Effect of urate-lowering therapy on the velocity of size reduction of tophi in chronic gout. Arthritis Rheum. 2002; 47: 356-60.

Perez-Ruiz F, Calabozo M, Pijoan JI, Herrero-Beites AM, Ruibal A. Effect of urate-lowering therapy on the velocity of size reduction of tophi in chronic gout. Arthritis Rheum. 2002; 47: 356-60.
Perez-Ruiz F, Lioté F. Lowering serum uric acid levels: what is the optimal target for improving clinical outcomes in gout? Arthritis Rheum. 2007; 57: 1324-8.

Perez-Ruiz F, Martin I, Canteli B. J Rheumatol. Ultrasonographic measurement of tophi as an outcome measure for chronic gout. 2007; 34: 1888-93.

Perez-Ruiz F1, Herrero-Beites AM, Carmona L. A twostage approach to the treatment of hyperuricemia in gout: the "dirty dish" hypothesis. Arthritis Rheum. 2011; 63: 4002-6.

Primatesta P, Plana E, Rothenbacher D. Gout treatment and comorbidities: a retrospective cohort study in a large US managed care population. BMC Musculoskelet Disord. 2011; $12: 103$.

Pui K, Gow PJ, Dalbeth N. Efficacy and tolerability of probenecid as urate-lowering therapy in gout; clinical experience in high-prevalence population. J Rheumatol. 2013; 40: 872-6.

Qaseem A, McLean RM, Starkey M, Forciea MA. Diagnosis of Acute Gout: A Clinical Practice Guideline From the American College of Physicians. Ann Intern Med. 2017; 166: 52-57.

Qaseem A, Harris RP, Forciea MA. Management of Acute and Recurrent Gout: A Clinical Practice Guideline From the American College of Physicians. Ann Intern Med. 2017; 166: 58-68.

Rainer TH, Cheng CH, Janssens HJ, Man CY, Tam LS, Choi YF, et al. Oral Prednisolone in the Treatment of Acute Gout: A Pragmatic, Multicenter, Double-Blind, Randomized Trial. Ann Intern Med. 2016; 164: 464-71.

Rees F, Jenkins W, Doherty M. Patients with gout adhere to curative treatment if informed appropriately: proof-ofconcept observational study. Ann Rheum Dis. 2013; 72: 826-30.

Reinders MK, van Roon EN, Houtman PM, Brouwers JR, Jansen TL. Biochemical effectiveness of allopurinol and allopurinol-probenecid in previously benzbromaronetreated gout patients. Clin Rheumatol. 2007; 26: 1459-65.

Reinders MK, Haagsma C, Jansen TL, van Roon EN, Delsing J, van de Laar MA, et al. A randomised controlled trial on the efficacy and tolerability with dose escalation of allopurinol 300-600 mg/day versus benzbromarone $100-200 \mathrm{mg} /$ day in patients with gout. Ann Rheum Dis. 2009; 68: 892-7.

Reinders MK, van Roon EN, Jansen TL, Delsing J, Griep EN, Hoekstra M, et al. Efficacy and tolerability of uratelowering drugs in gout: a randomised controlled trial of benzbromarone versus probenecid after failure of allopurinol. Ann Rheum Dis. 2009; 68: 51-6.

Report of Medical Research Council Working Party on Mild to Moderate Hypertension. Adverse reactions to bendrofluazide and propranolol for the treatment of mild hypertension. Lancet. 1981; 2:539-43.

Richette P, Brière C, Hoenen-Clavert V, Loeuille D, Bardin T. Rasburicase for tophaceous gout not treatable with allopurinol: an exploratory study. J Rheumatol. 2007; 34: 2093-8.

Richette P. Debulking the urate load to feel better. J Rheumatol. 2012; 39: 1311-3.

Richette P, Doherty M, Pascual E, Barskova V, Becce F, 
Castañeda-Sanabria J, et al. 2016 updated EULAR evidence-based recommendations for the management of gout. Ann Rheum Dis. 2017; 76: 29-42.

Roddy E, Zhang W, Doherty M. Concordance of the management of chronic gout in a UK primary-care population with the EULAR gout recommendations. Ann Rheum Dis. 2007; 66: 1311-5.

Rothenbacher D, Primatesta P, Ferreira A, Cea-Soriano L, Rodríguez LA. Frequency and risk factors of gout flares in a large population-based cohort of incident gout. Rheumatology (Oxford). 2011; 50: 973-81.

Roughley MJ, Belcher J, Mallen CD, Roddy E. Gout and risk of chronic kidney disease and nephrolithiasis: meta-analysis of observational studies. Arthritis Res Ther. 2015; 17: 90

Saag KG, Fitz-Patrick D, Kopicko J, Fung M, Bhakta N, Adler S et al. Arthritis Rheum 2014; 66(Suppl 10): L10. Lesinurad, a novel selective uric acid reabsorption inhibitor, in two phase III clinical trials: combination study of lesinurad in allopurinol standard of care inadequate responders (CLEAR 1 and 2).

Schlesinger N, Moore DF, Sun JD, Schumacher HR Jr. A survey of current evaluation and treatment of gout. J Rheumatol. 2006; 33: 2050-2.

Schlesinger N, De Meulemeester M, Pikhlak A, Yücel AE, Richard D, Murphy V, et al. Canakinumab relieves symptoms of acute flares and improves health-related quality of life in patients with difficult-to-treat Gouty Arthritis by suppressing inflammation: results of a randomized, doseranging study. Arthritis Res Ther. 2011; 13: R53.

Schlesinger N, Mysler E, Lin HY, De Meulemeester M, Rovensky J, Arulmani U, et al. Canakinumab reduces the risk of acute gouty arthritis flares during initiation of allopurinol treatment: results of a double-blind, randomised study. Ann Rheum Dis. 2011; 70: 1264-71.

Schlesinger N, Mysler E, Lin HY, De Meulemeester M, Rovensky J, Arulmani U, et al. Canakinumab reduces the risk of acute gouty arthritis flares during initiation of allopurinol treatment: results of a double-blind, randomised study. Ann Rheum Dis. 2011; 70: 1264-71.

Schumacher HR Jr, Becker MA, Wortmann RL, Macdonald PA, Hunt B, Streit J, et al. Effects of febuxostat versus allopurinol and placebo in reducing serum urate in subjects with hyperuricemia and gout: a 28-week, phase III, randomized, double-blind, parallel-group trial. Arthritis Rheum. 2008; 59: 1540-8.

Schumacher HR Jr, Evans RR, Saag KG, Clower J, Jennings W, Weinstein SP, et al. Rilonacept (interleukin-1 trap) for prevention of gout flares during initiation of uric acidlowering therapy: results from a phase III randomized, double-blind, placebo-controlled, confirmatory efficacy study. Arthritis Care Res (Hoboken). 2012; 64: 1462-70.

Seth R, Kydd AS, Falzon L, Bombardier C, van der Heijde DM, Edwards CJ. Preventing attacks of acute gout when introducing urate-lowering therapy: a systematic literature review. J Rheumatol. 2014; 92(Suppl): 42-7.

Siegel LB, Alloway JA, Nashel DJ. Comparison of adrenocorticotropic hormone and triamcinolone acetonide in the treatment of acute gouty arthritis. J Rheumatol. 1994; 21: 1325-7.
Singh JA, Reddy SG, Kundukulam J. Risk factors for gout and prevention: a systematic review of the literature. Curr Opin Rheumatol. 2011; 23: 192-202.

Singh JA, Reddy SG, Kundukulam J. Risk factors for gout and prevention: a systematic review of the literature. Curr Opin Rheumatol. 2011; 23: 192-202.

Sivera F, Andrés M, Carmona L, Kydd AS, Moi J, Seth R, et al. Multinational evidence-based recommendations for the diagnosis and management of gout: integrating systematic literature review and expert opinion of a broad panel of rheumatologists in the $3 \mathrm{e}$ initiative. Ann Rheum Dis. 2014; 73: 328-35.

So A, De Smedt T, Revaz S, Tschopp J. A pilot study of IL-1 inhibition by anakinra in acute gout. Arthritis Res Ther. 2007; 9: R28.

Sriranganathan MK, Vinik O, Falzon L, Bombardier C, van der Heijde DM, Edwards CJ. Interventions for tophi in gout: a Cochrane systematic literature review. J Rheumatol. 2014; 92 (Supple): 63-9.

Stamp LK, O'Donnell JL, Zhang M, James J, Frampton C, Barclay ML, Chapman PT. Using allopurinol above the dose based on creatinine clearance is effective and safe in patients with chronic gout, including those with renal impairment. Arthritis Rheum. 2011; 63: 412-21.

Stamp LK, Taylor WJ, Jones PB, Dockerty JL, Drake J, Frampton C, et al. Starting dose is a risk factor for allopurinol hypersensitivity syndrome: a proposed safe starting dose of allopurinol. Arthritis Rheum. 2012; 64: 2529-36.

Stamp LK, O’Donnell JL, Frampton C, Drake JM, Zhang M, Chapman PT. Arthritis Rheum. Clinically insignificant effect of supplemental vitamin $\mathrm{C}$ on serum urate in patients with gout: a pilot randomized controlled trial. 2013; 65: 1636-42.

Stocker SL, Graham GG, McLachlan AJ, Williams KM, Day RO. Pharmacokinetic and pharmacodynamic interaction between allopurinol and probenecid in patients with gout. J Rheumatol. 2011; 38: 904-10.

Strand V, Khanna D, Singh JA, Forsythe A, Edwards NL. Improved health-related quality of life and physical function in patients with refractory chronic gout following treatment with pegloticase: evidence from phase III randomized controlled trials. J Rheumatol. 2012; 39: 1450-7.

Sundy JS, Baraf HS, Yood RA, Edwards NL, GutierrezUrena SR, Treadwell EL, et al. Efficacy and tolerability of pegloticase for the treatment of chronic gout in patients refractory to conventional treatment: two randomized controlled trials. JAMA. 2011; 306: 711-20.

Sundy JS, Schumacher HR, Kivitz A, Weinstein SP, Wu R, King-Davis S, et al. Rilonacept for gout flare prevention in patients receiving uric acid-lowering therapy: results of RESURGE, a phase III, international safety study. J Rheumatol. 2014; 41: 1703-11.

Takagi H, Umemoto T. Atorvastatin therapy reduces serum uric acid levels: a meta-analysis of randomized controlled trials. Int J Cardiol. 2012; 157: 255-7.

Takahashi S, Moriwaki Y, Yamamoto T, Tsutsumi Z, Ka T, Fukuchi M. Ann Rheum Dis. Effects of combination treatment using anti-hyperuricaemic agents with fenofibrate and/or losartan on uric acid metabolism. 2003; 62: 572-5. 
Tassaneeyakul W, Jantararoungtong T, Chen P, Lin PY, Tiamkao $\mathrm{S}$, Khunarkornsiri U, et al. Strong association between HLA-B*5801 and allopurinol-induced Stevens-Johnson syndrome and toxic epidermal necrolysis in a Thai population. Pharmacogenet Genomics. 2009; 19: 704-9.

Taylor TH, Mecchella JN, Larson RJ, Kerin KD, Mackenzie TA. Initiation of allopurinol at first medical contact for acute attacks of gout: a randomized clinical trial. Am J Med. 2012; 125: 1126-1134.e7.

Te Karu L, Bryant L, Elley CR. Maori experiences and perceptions of gout and its treatment: a kaupapa Maori qualitative study. J Prim Health Care. 2013; 5: 214-22.

Teng GG, Ang LW, Saag KG, Yu MC, Yuan JM, Koh WP. Mortality due to coronary heart disease and kidney disease among middle-aged and elderly men and women with gout in the Singapore Chinese Health Study. Ann Rheum Dis. 2012; 71: 924-8.

Terkeltaub RA, Furst DE, Bennett K, Kook KA, Crockett RS, Davis MW. High versus low dosing of oral colchicine for early acute gout flare: Twenty-four-hour outcome of the first multicenter, randomized, double-blind, placebocontrolled, parallel-group, dose-comparison colchicine study. Arthritis Rheum. 2010; 62: 1060-8.

Terkeltaub RA, Furst DE, Digiacinto JL, Kook KA, Davis MW. Novel evidence-based colchicine dose-reduction algorithm to predict and prevent colchicine toxicity in the presence of cytochrome P450 3A4/P-glycoprotein inhibitors. Arthritis Rheum. 2011; 63: 2226-37.

Terkeltaub RA, Schumacher HR, Carter JD, Baraf HS, Evans RR, Wang J, et al. Rilonacept in the treatment of acute gouty arthritis: a randomized, controlled clinical trial using indomethacin as the active comparator. Arthritis Res Ther. 2013; 15: R25.

Tufan A, Dede DS, Cavus S, Altintas ND, Iskit AB, Topeli A. Rhabdomyolysis in a patient treated with colchicine and atorvastatin. Ann Pharmacother. 2006; 40: 1466-9.

Ungprasert P, Cheungpasitporn W, Crowson CS, Matteson EL. Individual non-steroidal anti-inflammatory drugs and risk of acute kidney injury: A systematic review and meta-analysis of observational studies. Eur J Intern Med. 2015; 26: 285-91.

Vázquez-Mellado J1, Morales EM, Pacheco-Tena C, Burgos-Vargas R. Relation between adverse events associated with allopurinol and renal function in patients with gout. Ann Rheum Dis. 2001; 60: 981-3.
Wallace SL, Singer JZ, Duncan GJ, Wigley FM, Kuncl RW. Renal function predicts colchicine toxicity: guidelines for the prophylactic use of colchicine in gout. J Rheumatol. 1991; 18: 264-9.

Wechalekar MD, Vinik O, Moi JH, Sivera F, van Echteld IA, van Durme $\mathrm{C}$, et al. The efficacy and safety of treatments for acute gout: results from a series of systematic literature reviews including Cochrane reviews on intraarticular glucocorticoids, colchicine, nonsteroidal antiinflammatory drugs, and interleukin-1 inhibitors. J Rheumatol 2014; 92 (Suppl.): 15-25.

Weisskopf MG, O'Reilly E, Chen H, Schwarzschild MA, Ascherio A. Am J Epidemiol. Plasma urate and risk of Parkinson's disease. 2007; 166: 561-7.

Wortmann RL, Macdonald PA, Hunt B, Jackson RL. Effect of prophylaxis on gout flares after the initiation of uratelowering therapy: analysis of data from three phase III trials. Clin Ther. 2010; 32: 2386-97.

Wu EQ, Patel PA, Mody RR, Yu AP, Cahill KE, Tang J, et al. Frequency, risk, and cost of gout-related episodes among the elderly: does serum uric acid level matter? J Rheumatol. 2009; 36: 1032-40.

Würzner G, Gerster JC, Chiolero A, Maillard M, Fallab-Stubi CL, Brunner HR, et al. Comparative effects of losartan and irbesartan on serum uric acid in hypertensive patients with hyperuricaemia and gout. J Hypertens. 2001; 19: 1855-60.

Ye P1, Yang S, Zhang W, Lv Q, Cheng Q, Mei M, et al. Efficacy and tolerability of febuxostat in hyperuricemic patients with or without gout: a systematic review and meta-analysis. Clin Ther. 2013; 35: 180-9.

Zhang Y, Chen C, Choi H, Chaisson C, Hunter D, Niu J, et al. Purine-rich foods intake and recurrent gout attacks. Ann Rheum Dis. 2012; 71: 1448-53.

Zhang Y, Neogi T, Chen C, Chaisson C, Hunter DJ, Choi HK. Cherry consumption and decreased risk of recurrent gout attacks. Arthritis Rheum. 2012; 64: 4004-11.

Zineh I, Mummaneni P, Lyndly J, Amur S, La Grenade LA, Chang SH, et al. Allopurinol pharmacogenetics: assessment of potential clinical usefulness. Pharmacogenomics. 2011; 12: 1741-9.

Zineh I, Mummaneni P, Lyndly J, Amur S, La Grenade LA, Chang SH, et al. Allopurinol pharmacogenetics: assessment of potential clinical usefulness. Pharmacogenomics. 2011; 12: 1741-9. 


\section{REFERENCES}

1. Trifirò G, Morabito P, Cavagna L, et al. Epidemiology of gout and hyperuricaemia in Italy during the years 2005-2009: a nationwide population-based study. Ann Rheum Dis. 2013; 72 : 694-700.

2. Pascual E, Addadi L, Andrés M, Sivera F. Mechanisms of crystal formation in gout-a structural approach. Nat Rev Rheumatol. 2015; 11: 725-30.

3. So AK, Martinon F. Inflammation in gout: mechanisms and therapeutic targets. Nat Rev Rheumatol. 2017; 13: 639-47.

4. Scirè CA, Manara M, Cimmino MA, et al. Gout impacts on function and health-related quality of life beyond associated risk factors and medical conditions: results from the KING observational study of the Italian Society for Rheumatology (SIR). Arthritis Res Ther. 2013; 15: R101.

5. Degli Esposti L, Desideri G, Saragoni S, et al. Hyperuricemia is associated with increased hospitalization risk and healthcare costs: Evidence from an administrative database in Italy. Nutr Metab Cardiovasc Dis. 2016; 26: 951-61.

6. Kuo CF, Luo SF. Gout: Risk of premature death in gout unchanged for years. Nat Rev Rheumatol. 2017 ; 13: 200-1.

7. Fisher MC, Rai SK, Lu N, et al. The unclosing premature mortality gap in gout: a general population-based study. Ann Rheum Dis. 2017; 76: 1289-94.

8. Mantarro S, Capogrosso-Sansone A, Tuccori $\mathrm{M}$, et al. Allopurinol adherence among patients with gout: an Italian general practice database study. Int J Clin Pract. 2015; 69: 757-65.

9. Ten Brinck RM, de Moel EC, van der Pol JA, et al. Is optimising gout treatment the key to closing the mortality gap in gout patients? Ann Rheum Dis. 2018; 77: e2.

10. Manara M, Bortoluzzi A, Favero M, et al. Italian Society of Rheumatology recommendations for the management of gout. Reumatismo. 2013; 65: 4-21.

11. Zhang W, Doherty M, Pascual E, et al. EULAR evidence based recommendations for gout. Part I: Diagnosis. Report of a task force of the Standing Committee for International Clinical Studies Including Therapeutics (ESCISIT). Ann Rheum Dis. 2006; 65: 1301-11.

12. Zhang W, Doherty M, Bardin T, et al. EULAR evidence-based recommendations for gout. Part II: Management. Report of a task force of the EULAR Standing Committee for International Clinical Studies Including Therapeutics (ESCISIT). Ann Rheum Dis. 2006; 65: 1312-24.

13. Pasina L, Brucato AL, Djade CD, et al. Inappropriate prescription of allopurinol and febuxostat and risk of adverse events in the elderly: results from the REPOSI registry. Eur J Clin Pharmacol. 2014; 70: 1495-503.

14. Khanna D, Fitzgerald JD, Khanna PP, et al. 2012 American College of Rheumatology guidelines for management of gout. Part 1: systematic nonpharmacologic and pharmacologic therapeutic approaches to hyperuricemia. Arthritis Care Res (Hoboken). 2012; 64: 1431-46.

15. Khanna D, Khanna PP, Fitzgerald JD, et al. 2012 American College of Rheumatology guidelines for management of gout. Part 2: therapy and antiinflammatory prophylaxis of acute gouty arthritis. Arthritis Care Res (Hoboken). 2012; 64: 1447-61.

16. Sivera F, Andrés M, Carmona L, et al. Multinational evidence-based recommendations for the diagnosis and management of gout: integrating systematic literature review and expert opinion of a broad panel of rheumatologists in the 3e initiative. Ann Rheum Dis. 2014; 73: 328-35.

17. Richette P, Doherty M, Pascual E, et al. 2016 updated EULAR evidence-based recommendations for the management of gout. Ann Rheum Dis. 2017; 76: 29-42.

18. Kiltz U, Smolen J, Bardin T, et al. Treat-totarget (T2T) recommendations for gout. Ann Rheum Dis. 2017; 76: 632-8.

19. Qaseem A, McLean RM, Starkey M, Forciea MA. Diagnosis of acute gout: a clinical practice guideline from the American College of Physicians. Ann Intern Med. 2017; 166: 52-7.

20. Qaseem A, Harris RP, Forciea MA. Management of acute and recurrent gout: a clinical practice guideline from the American College of Physicians. Ann Intern Med. 2017; 166: 58-68.

21. Hui M, Carr A, Cameron S, et al. The British Society for Rheumatology Guideline for the Management of Gout. Rheumatology (Oxford). 2017; 56: e1-20.

22. Neogi T, Jansen TL, Dalbeth N, et al. 2015 Gout Classification Criteria: an American College of Rheumatology/European League Against Rheumatism collaborative initiative. Arthritis Rheumatol. 2015; 67: 2557-68.

23. Newberry SJ, FitzGerald JD, Motala A, et al. Diagnosis of gout: a systematic review in support of an American College of Physicians clinical practice guideline. Ann Intern Med. 2017; 166: 27-36.

24. Fervers B, Burgers JS, Haugh MC, et al. Adaptation of clinical guidelines: literature review and proposition for a framework and procedure. Int J Qual Health Care. 2006; 18: 167-76.

25. Fervers B, Burgers JS, Voellinger R, et al. Guideline adaptation: an approach to enhance efficiency in guideline development and improve utilisation. BMJ Qual Saf. 2011; 20: 228-36. 
26. Brouwers MC, Kho ME, Browman GP, et al. AGREE II: advancing guideline development, reporting and evaluation in health care. CMAJ. 2010; 182: e839-42.

27. Oxford Centre for Evidence-based Medicine. Levels of evidence; March 2009. Available from: http://www.cebm.net/oxford-centre-evidence-based-medicine-levels-evidencemarch-2009/

28. Brouwers MC, Kerkvliet K, Spithoff K. The AGREE Reporting Checklist: a tool to improve reporting of clinical practice guidelines. BMJ. 2016; 352: i1152.

29. Beard SM, von Scheele BG, Nuki G, Pearson IV. Cost-effectiveness of febuxostat in chronic gout. Eur J Health Econ. 2014; 15: 453-63.

30. Jutkowitz E, Choi HK, Pizzi LT, Kuntz KM. Cost-effectiveness of allopurinol and febuxostat for the management of gout. Ann Intern Med. 2014; 161: 617-26.

31. Agenzia Italiana del Farmaco. Synacthen - AIC: 020780. Foglio illustrativo. Available since September $27^{\text {th }}$, 2017. https://farmaci.agenziafarmaco.gov.it/aifa/servlet/PdfDownloadSe rvlet?pdfFileName=footer_004375_020780_ FI.pdf\&retry $=0 \&$ sys $=$ m0b113 Accessed: April $25^{\text {th }}, 2018$.

32. European Medicine Agency. Adenuric - EMEA/ H/C/000777 -PSUSA/00001353/201704. European public assessment report - Product Information. Last updated March 27th, 2018. http://www. ema.europa.eu/docs/en_GB/document_library/ EPAR_-_Product_Information/human/000777/ WC500021812.pdf Accessed: April 25 $5^{\text {th }}, 2018$.

33. European Medicine Agency. Zurampic EMEA/H/C/003932 - IA/0008. European public assessment report - Product Information. Last updated July $6^{\text {th }}, 2017$. http://www. ema.europa.eu/docs/en_GB/document_library/EPAR_-_Product_Information/human/003932/WC500203066.pdf Accessed: April $25^{\text {th }}, 2018$.
34. Agenzia Italiana del Farmaco. Zyloric AIC: 021259. Foglio illustrativo. Available since June $10^{\text {th }}, 2016$. https://farmaci.agenziafarmaco.gov.it/aifa/servlet/PdfDownloadSe rvlet?pdfFileName=footer_007046_021259_ FI.pdf \& retry $=0 \&$ sys $=$ m0b113 Accessed: April $25^{\text {th }}, 2018$.

35. European MedicineAgency. Krystexxa-EMEA/ H/C/002208-PSUSA/00010046/201501. European public assessment report - Product Information. Last updated July 22 2016. http://www.ema.europa.eu/docs/en_GB/document_library/EPAR_-_Product_Information/ human/002208/WC500138318.pdf Accessed: April 25 $5^{\text {th }}, 2018$.

36. Singh JA, Edwards NL. EULAR gout treatment guidelines by Richette et al.: uric acid and neurocognition. Ann Rheum Dis. 2018; 77: e20.

37. Richette P, Doherty M, Pascual E, Bardin T. SUA levels should not be maintained $<3 \mathrm{mg} /$ dl for several years. Response to 'EULAR gout treatment guidelines by Richette et al: uric acid and neurocognition by Singh et al'. Ann Rheum Dis. 2018; 77: e21.

38. Kuo CF. A changing landscape of gout: comorbidity matters. J Rheumatol. 2018; 45: 454-5.

39. Scirè CA, Rossi C, Punzi L, et al. Change gout: how to deal with this "silently-developing killer" in everyday clinical practice. Curr Med Res Opin. 2018; 34: 1411-7.

40. White WB, Saag KG, Becker MA, et al. Cardiovascular safety of febuxostat or allopurinol in patients with gout. N Engl J Med. 2018; 378 : 1200-10.

41. Dalbeth N, Bardin T, Doherty M, et al. Discordant American College of Physicians and international rheumatology guidelines for gout management: consensus statement of the Gout, Hyperuricemia and Crystal-Associated Disease Network (G-CAN). Nat Rev Rheumatol. 2017; 13: 561-8. 